\author{
Estela Maria Barim
}

\title{
CARACTERIZAÇÃO DO CONSUMO ALIMENTAR DE FRUTAS, VERDURAS E LEGUMES EM ADULTOS NA ATENÇÃO PRIMÁRIA
}

Dissertação apresentada ao Programa de Pósgraduação de Saúde Coletiva, área de concentração Saúde Pública da Faculdade de Medicina, Universidade Paulista "Julio de Mesquita Filho", Campus de Botucatu.

Orientadora: Prof ${ }^{\mathrm{a}}$.Dr ${ }^{\mathrm{a}}$. Elen Rose Lodeiro Castanheira

Co-orientadora: Prof ${ }^{\mathrm{a}} \mathrm{Dr}^{\mathrm{a}}$ Maria Antonieta de Barros Leite Carvalhaes 
FICHA CATALOGRÁFICA ELABORADA PELA SEÇÃO TÉCNICA DE AQUISIÇÃO E TRATAMENTO DA INFORMAÇÃO

DIVISÃO TÉCNICA DE BIBLIOTECA E DOCUMENTAÇÃO - CAMPUS DE BOTUCATU - UNESP BIBLIOTECÁRIA RESPONSÁVEL: Selma Maria de Jesus

Barim, Estela Maria.

Caracterização do consumo alimentar de frutas, verduras e legumes em adultos na atenção primária / Estela Maria Barim. - Botucatu, 2010.

Dissertação (mestrado) - Faculdade de Medicina de Botucatu, Universidade Estadual Paulista, 2010

Orientadora: Elen Rose Lodeiro Castanheira

Co-orientadora: Maria Antonieta de Barros Leite

Assunto CAPES: 40600009

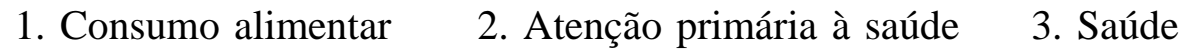
coletiva

Palavras-chave: Atenção primária; Consumo alimentar; Determinantes;

Frutas; Legumes; Verduras 


\section{Dedicatária}

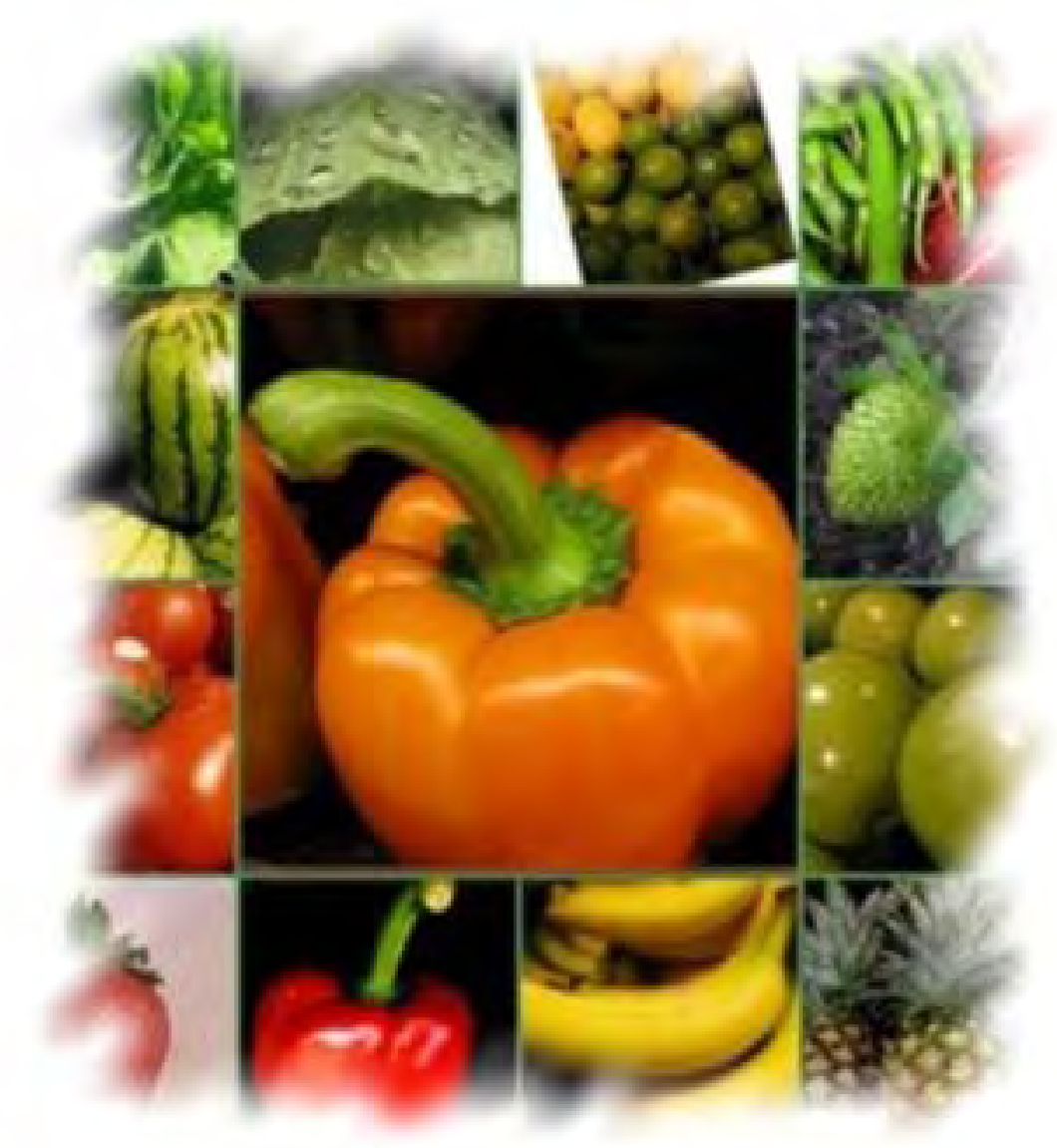


As minhas queridas cunhadas Maria Laura, pela apaia e pela exempla de paixãa à pesquisa. Maria Isabel, pela incentiva canstante.

$\mathscr{A}$ minha querida sagra - mãe Gudith, pela exempla de persistencia e pela apaia incandicianal em tadas as mamentas.

Aa mew amar Cyra, campanheira em tadas as haras e grande incentivadar.

Muita abrigada Famúlia!! 


\section{Agradecimenta Especial}

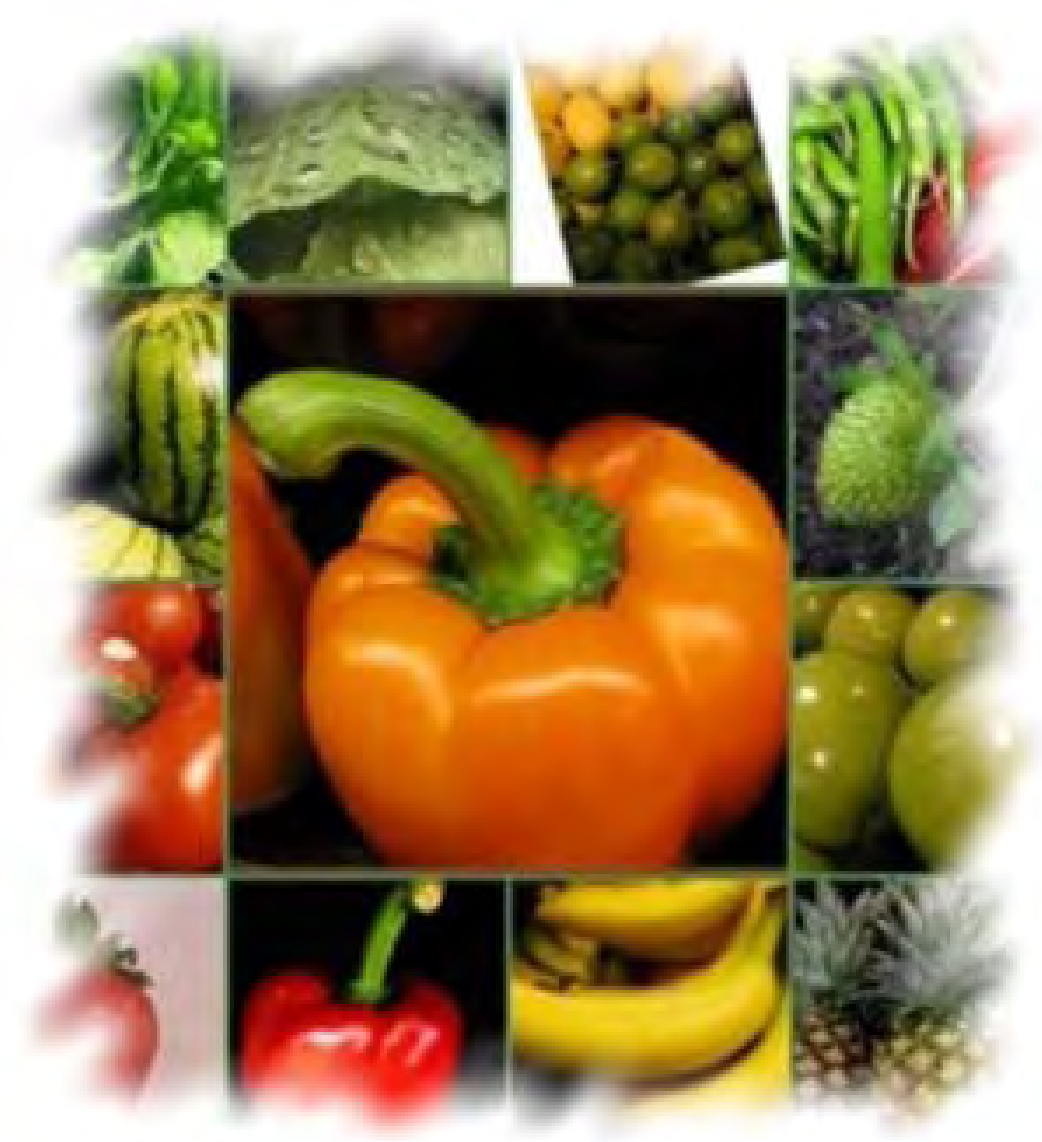


A Praf $D_{r}^{a}$ Elen Rase Ladeira Castanheira, pela acalhimenta, amizade e carinha na arientaçãa deste trabalha.

A Prof Dr $^{a}$ Maria Antanieta de Barras Leite Carvalhaes - Neneca, pela exempla prafissianal, ensinamentas e amizade. Sua ajuda e incentiva faram fundamentais, para a realizaçãa deste trabalho. 


\section{Agradecimentas}

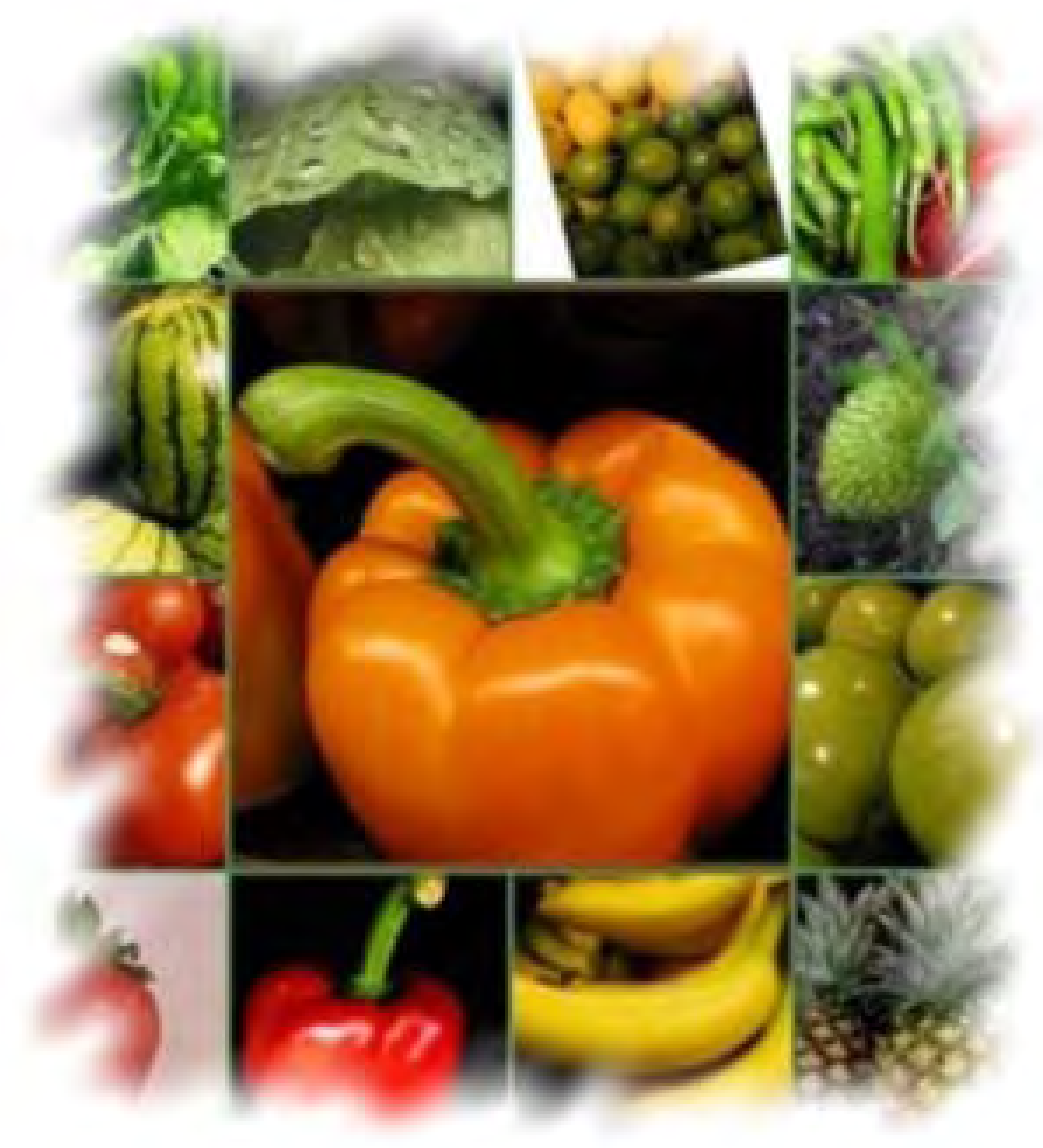


Aa Praf. Dr. Gasé Eduarda Carrente, pela cantriluiçãa inestimável na metadalagia e análise estatística deste trabalha, e pela atençãa dispensada.

Aa diretar da Centra de Saúde Escala - FMP - Unesp, Praf. Dr. Antania de Pádua Pithan Cyrina, pela incentiva, apaia e valarizaçãa deste trabalha.

As minhas queridas amigas Cássia Marisa Manael, Luciana Cristina Parenti e Márcia Cristina Faglia Ramas, pela incentiva canstante e amizade sincera.

A Thaís Maranhãa Negreiras e Aline Graziele da Silva Pereira, pela auxilia na caleta das dadas, incentiva e amizade.

À Maria Stella Rasati de Cliveira, pela auxilia na vealizaçãa das cálculas nutricianais e amizade.

As Mutricianistas Maíra Barreta Malta, Vivian Maria $\mathcal{S}$. Paranhas, Carina Alcalá Carcia e Maria Marcisa Faggian Carcia, pela apaia e amizade.

Aas calegas da Área da Saúde da Adulta e Arquira Médica, pela essencial apaia prestada, na realizaçãa deste trabalha.

Aas funcianárias da Centra de Saúde Escala - FMP Unesp, pela apaia e incentiva.

Aas Prafessares Dantares Luis Carlas Ciarala e Regina Mara Fisherg, pelas impartantes cantriluiçães e sugestães aferecidas, durante a exame de qualificaçãa. 
Agradecimentas

Aas prafessares da Departamenta de Saúde Pública, pelas ensinamentas ministradas.

Aas funcianárias da Departamenta de Saúde Púlulica, Ana Paula, Elaine, Wagner e Lucilene e também aas funcianárias da Seçãa de Pás-graduaçãa Natanael, Regina, Andréia, Lilian e Ganete, pela auxilia e atençãa dispensada.

As funcianárias da Bililiateca da FMB - Unesp, Marluci Betini, Rasemary Cristina da Silva e Selma Maria de Yesus, pela auxilia e atençãa dispensada. 


\section{Lista de Siglas}

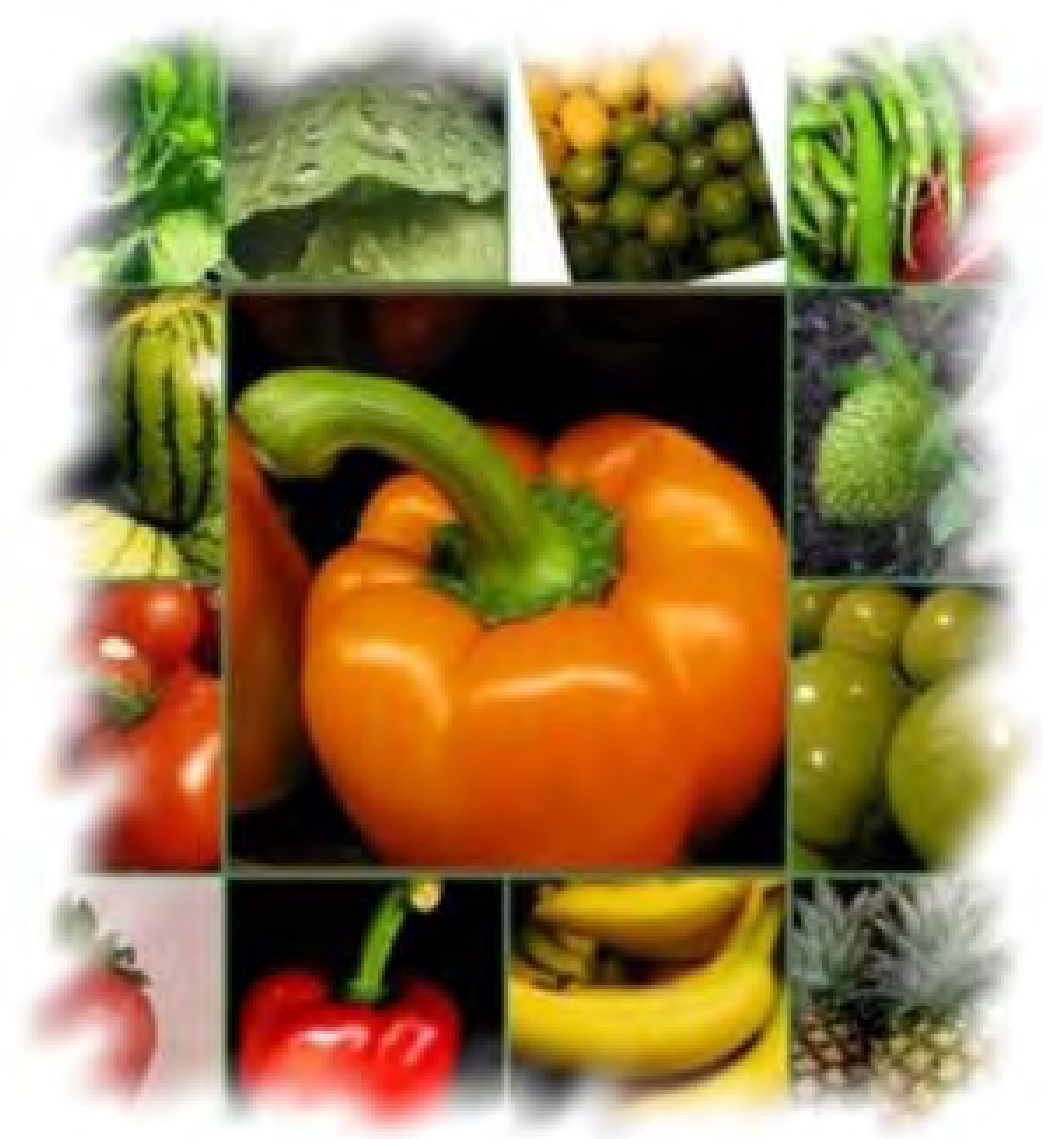


Fr,V\& L - $\quad$ frutas, verduras e legumes

DANT - doenças e agravos crônicos não transmissíveis

OMS - $\quad$ Organização Mundial de Saúde

WHO - $\quad$ World Health Organization (Organização Mundial de Saúde)

POF - $\quad$ Pesquisa de Orçamento Familiar

WCRF - $\quad$ World Cancer Research Fund (Fundo Mundial para a Pesquisa em Câncer)

AICR - $\quad$ American Institute for Cancer Research (Instituto Americano para Pesquisa em Câncer)

INCA - Instituto Nacional do Câncer

IBRA - Instituto Brasileiro de Orientação Alimentar

WHS - $\quad$ World Health Survey (Inquérito sobre a Saúde Mundial)

IQD - $\quad$ índice de qualidade da dieta

CSE - $\quad$ Centro de Saúde Escola

FMB - $\quad$ Faculdade de Medicina de Botucatu

DSTIAIDS - doenças sexualmente transmissíveis e síndrome da imunodeficiência adquirida

ANI - $\quad$ atendimento nutricional individual

AEG - $\quad$ atividade educativa em grupo

AESE - $\quad$ atividade educativa em sala de espera

MTD - $\quad$ modelo teórico de determinação do comportamento alimentar de indivíduos adultos

IMC - $\quad$ índice de massa corpórea

SISVAN - manual de técnicas e orientação da Vigilância Alimentar e Nutricional

DCV - doença cardiovascular

NutWin - $\quad$ Programa de Apoio à Nutrição

TACO - $\quad$ Tabela Brasileira de Composição de Alimentos

SAS - $\quad$ Statistical Analysis System 
DP - $\quad$ desvio padrão

CA - $\quad$ consumo de Fr,V\&L em gramas ajustado

PE - $\quad$ consumo de Fr, V\&L em porcentagem da energia total

SUS - $\quad$ Sistema Único de Saúde

IBGE - Instituto Brasileiro de Geografia e Estatística 


\section{Lista de Tlustraçães}

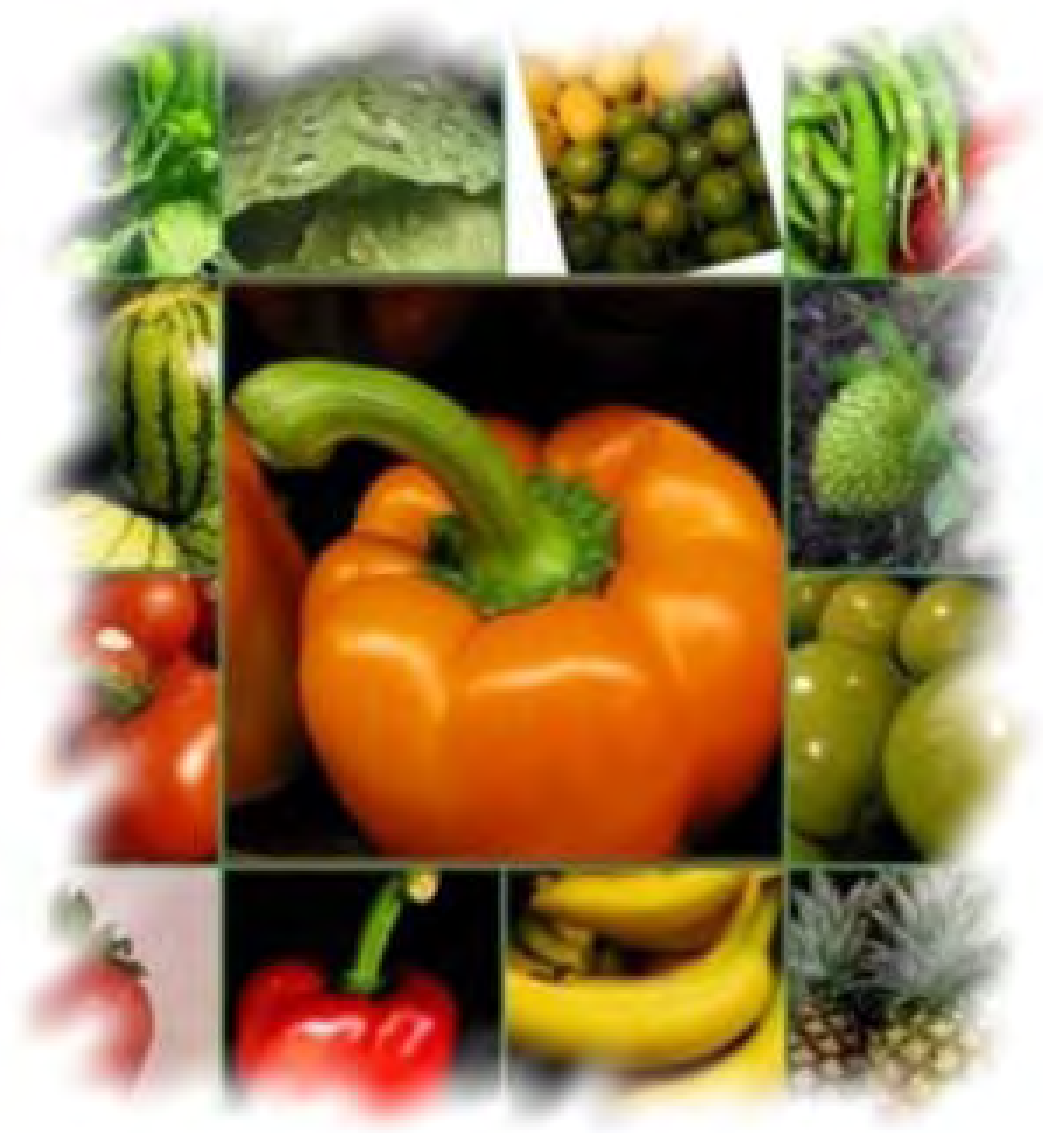


Figura 1- Modelo teórico de determinação do comportamento alimentar no adulto (M.T.D.)

Figura 2- Modelo de análise do consumo de frutas, verduras e legumes em adultos usuários de uma de Unidade de Saúde.

Figura 3 - Box-plot referente à variável consumo de Fr,V\&L em porcentagem da energia da dieta.

Figura 4 - Box-plot referente à variável consumo de Fr,V\&L em gramas. 


\section{Lista de Quadras}

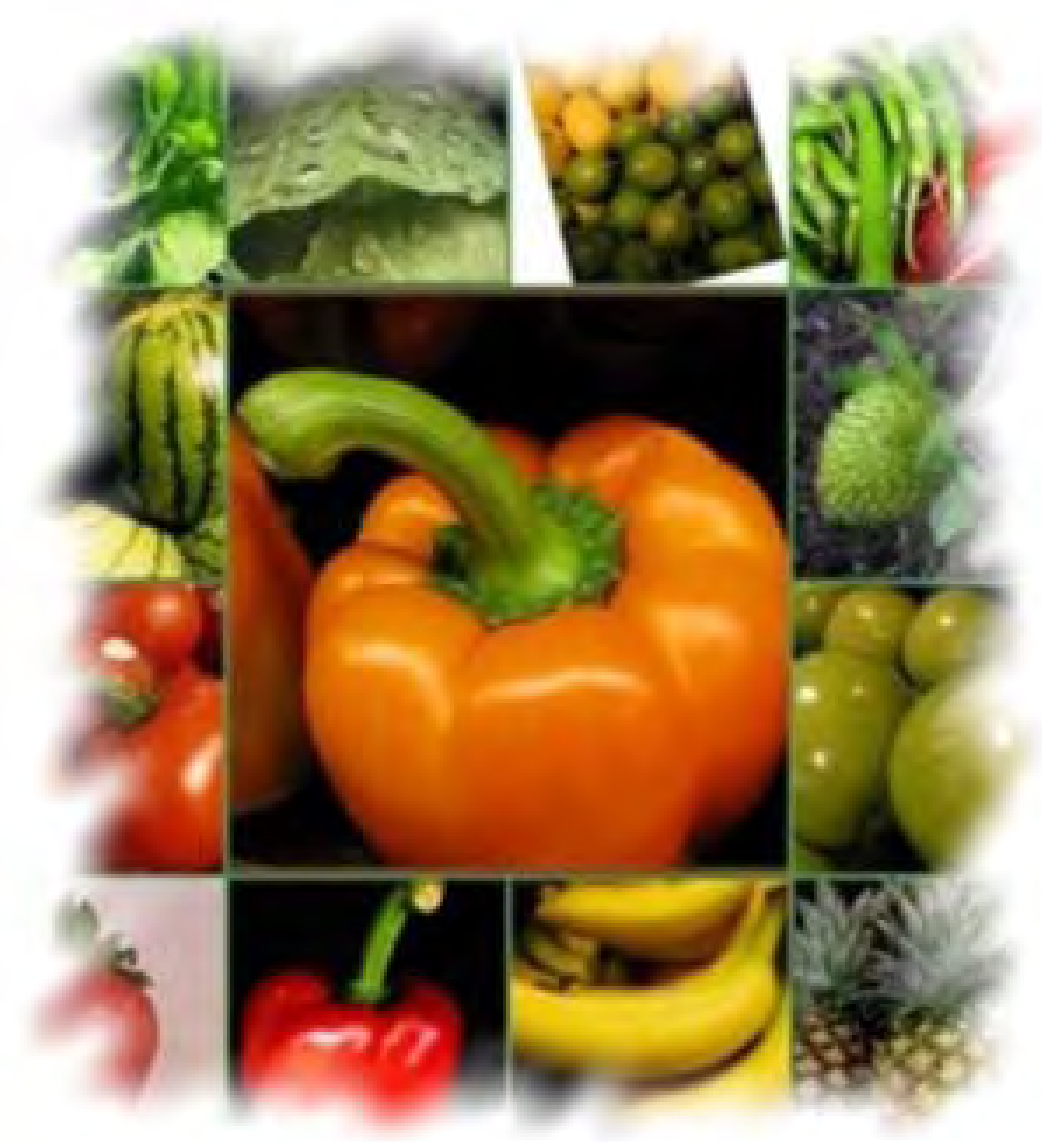


Lista de Quadras

Quadro 1 - Pontos de Corte para o Índice de Massa Corpórea $\mathrm{kg} / \mathrm{m}^{2}$

50

Quadro 2 - Categorização quanto ao consumo de Fr,V\&L em gramas e em porcentagem de energia, segundo as recomendações da OMS e WCRF...

53 


\section{Lista de Tabelas}

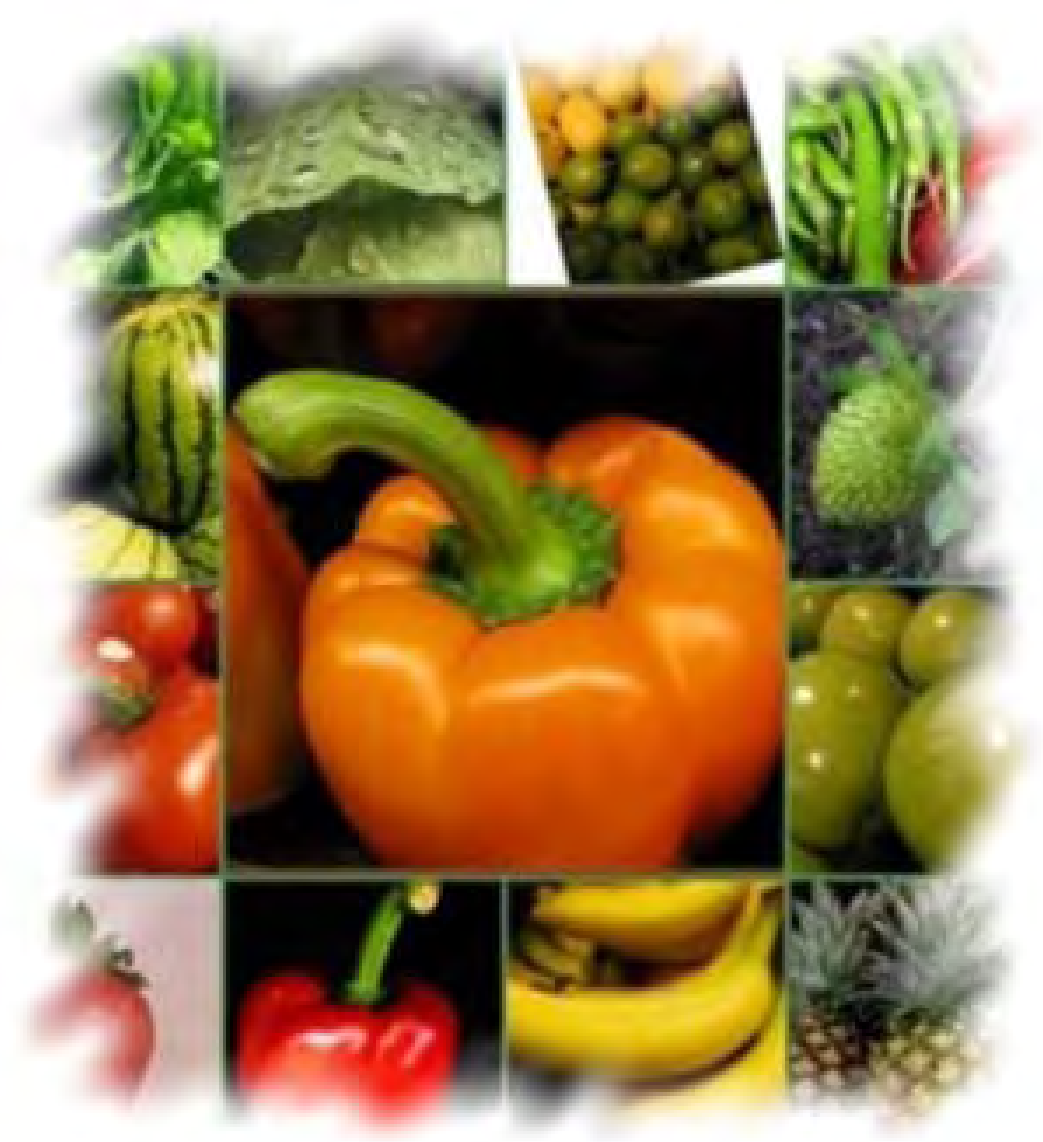


Tabela 1 - Distribuição numérica e percentual da população estudada segundo características demográficas, socioeconômica, nutricional e presença de morbidades específicas $(\mathrm{N}=181)$.

Tabela 2 - Distribuição numérica e percentual da população estudada segundo a participação dos indivíduos nas diferentes modalidades de atendimento e abordagem da individual ou em grupo oferecidas na área de Atenção ao Adulto $(\mathrm{N}=181)$......

Tabela 3 - Valores médios, medianos e percentis do consumo diário de Fr,V\&L bruto e ajustado, em gramas (g), energia (Cal), porcentagem (\%) de energia da dieta e a energia (Cal) total da dieta consumida pelos entrevistados $(\mathrm{N}=181)$

Tabela 4 - Distribuição dos indivíduos estudados segundo categoria de consumo de Fr,V\&L em gramas e porcentagem da energia da dieta, conforme as recomendações da OMS e WCRF $(\mathrm{N}=181)$.

Tabela 5 - Distribuição numérica e porcentagem em ordem decrescente de indivíduos segundo os alimentos consumidos do grupo de Fr,V\&L (N=181).

Tabela 6 - Distribuição numérica e porcentagem em ordem decrescente de indivíduos segundo os alimentos consumidos do grupo das Frutas ( $\mathrm{N}=181)$

Tabela 7- Distribuição numérica e porcentagem em ordem decrescente de indivíduos segundo os alimentos consumidos do grupo das Verduras $(\mathrm{N}=181)$.

Tabela 8 - Distribuição numérica e porcentagem em ordem decrescente de indivíduos segundo os alimentos consumidos do grupo dos Legumes $(N=181)$.

Tabela 9 - Alimentos consumidos em ordem decrescente de sua contribuição para o consumo total de $\mathrm{Fr}, \mathrm{V} \& \mathrm{~L}$, em porcentagem (\%) da energia e em gramas.

Tabela 10 - Frutas consumidas em ordem decrescente de sua contribuição para o consumo deste grupo, em porcentagem (\%) da energia e em gramas (g).

Tabela 11 - Verduras consumidas em ordem decrescente de sua contribuição para o consumo deste grupo, em porcentagem (\%) da energia e em gramas ( $\mathrm{g}$ ). 
Tabela 12 - Legumes consumidos em ordem decrescente de sua contribuição para o consumo deste grupo, em porcentagem (\%) da energia e em gramas $(\mathrm{g})$...

Tabela 13 - Comparação entre o consumo de Fr,V\&L em gramas ajustado e em porcentagem de energia entre os fatores selecionados.

Tabela 14 - Comparação entre o consumo de Fr,V\&L em gramas ajustado e em porcentagem de energia segundo o uso do serviço de saúde: atendimento nutricional individual (ANI) e atividade educativa em grupo (AEG) no último ano.

Tabela 15 - Coeficiente de correlação e p-valor para as variáveis consumo de Fr,V\&L em gramas ajustado e em porcentagem da energia total com idade e IMC. 


\section{Resuma}

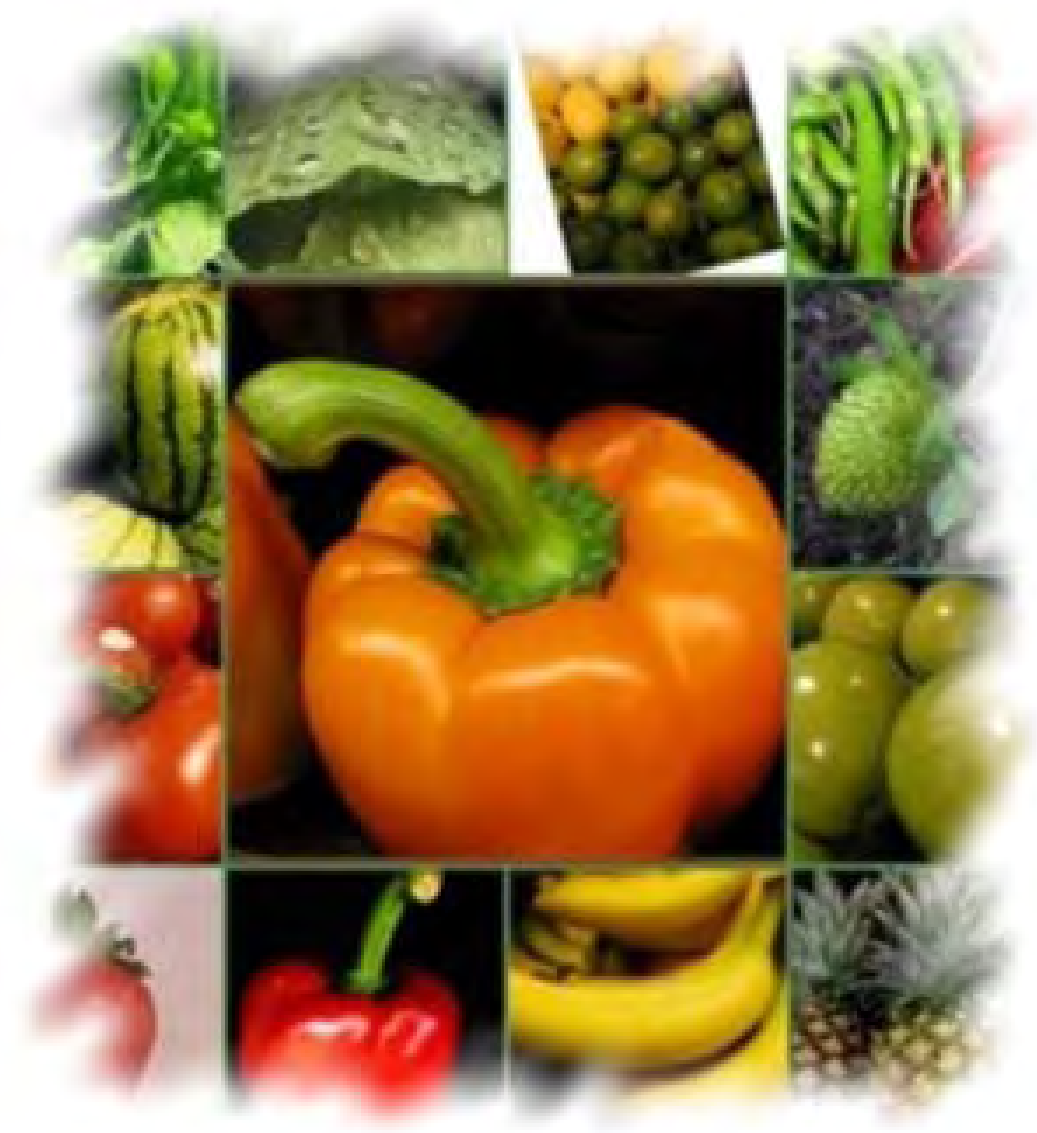


A alimentação inadequada e o consumo insuficiente de frutas, verduras e legumes estão relacionadas à maior prevalência de doenças e agravos crônicos não transmissíveis, como diabetes, obesidade, doenças cardiovasculares e alguns tipos de cânceres. A complexidade dos determinantes relacionados a essa situação tem exigido o desenvolvimento de investigações que ampliem o conhecimento científico sobre os diferentes aspectos envolvidos. As doenças e agravos crônicos não transmissíveis são de etiologia multifatorial e compartilham vários fatores de riscos modificáveis entre eles a alimentação inadequada, com destaque para a ingestão insuficiente de frutas, verduras e legumes. Considerando a importância desse grupo alimentar para a saúde em geral e redução das doenças e agravos crônicos não transmissíveis, o presente estudo visou descrever o consumo de frutas, verduras e legumes e identificar os fatores associados a esse consumo em uma população adulta, usuária de um serviço público de atenção primária à saúde. Para descrever o consumo de frutas, verduras e legumes foi utilizado recordatório alimentar de 24 horas e realizado método de ajuste pelo consumo energético. Para a obtenção das informações socioeconômicas, antropométricas e sobre os fatores potencialmente associados ao consumo de frutas, verduras e legumes foi utilizado um formulário, construído para o presente estudo, guiado por um modelo teórico de determinação do comportamento alimentar de indivíduos adultos. A população estudada foi formada, predominantemente, por mulheres de meia idade e baixa escolaridade, com excesso de peso corporal e alta prevalência de doenças crônicas. O consumo diário médio de frutas, verduras e legumes, ajustado por energia, foi igual a 281,3 gramas e a porcentagem média de energia da dieta fornecida por este grupo alimentar foi igual a 8,7\%. Dos indivíduos avaliados 40,9 \% alcançaram a recomendação da Organização Mundial da Saúde de consumo mínimo igual a 9\% da energia total da dieta. Houve associação do consumo de frutas, verduras e legumes (em porcentagem de energia) com sexo, sendo o consumo maior entre as mulheres; com estado nutricional, sendo o maior valor observado em indivíduos com sobrepeso e com participação em atendimento nutricional individual, na comparação com não 
participantes. Observou-se na população estudada consumo médio maior do que o observado em amostras representativas da população brasileira, possivelmente devido aumento da idade e condição de saúde alterada dos indivíduos, que usam mais o serviço de saúde, estando expostos a abordagens nutricionais e mais suscetíveis a mudanças alimentares. Conclui-se que há necessidade de ações visando incentivo do consumo deste grupo alimentar aos usuários mais jovens, homens, menos escolarizados e não participantes de ações individuais de orientação alimentar. O que exigiria além do aperfeiçoamento das estratégias voltadas aos usuários, o desenvolvimento de ações voltadas à comunidade.

Palavras chave: consumo alimentar, frutas, verduras e legumes, determinantes, atenção primária. 


\section{Alestract}

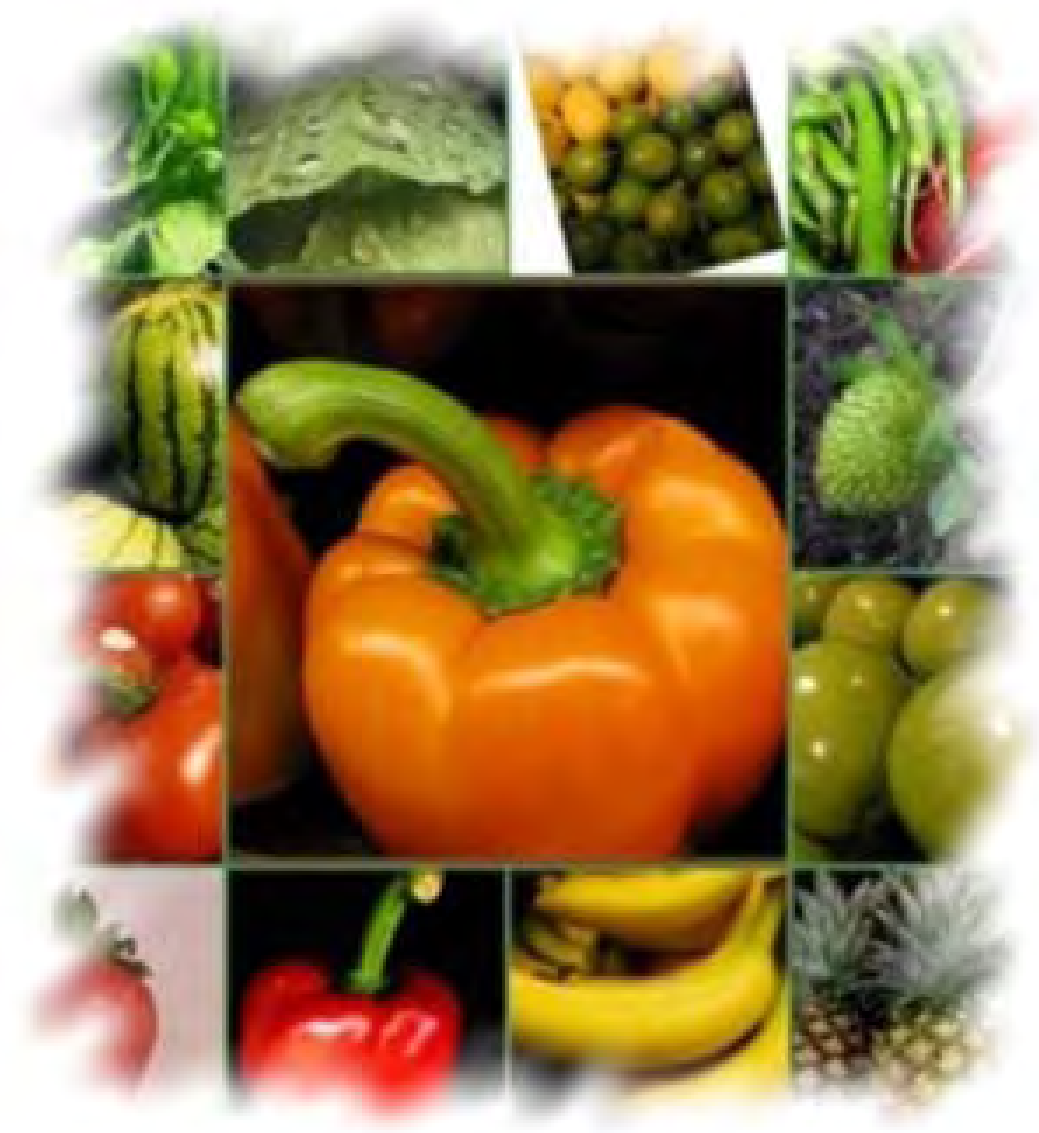




\section{CHARACTERIZATION OF DIETARY INTAKE OF FRUIT, VEGETABLES AND LEGUMES BY ADULTS IN PRIMARY CARE}

Inadequate diet and insufficient intake of fruit, vegetables and legumes are related to higher prevalence of non-transmittable chronic diseases and aggravations, such as diabetes, obesity, cardiovascular diseases and some cancer types. The complexity of determinants related to this situation has required the development of investigations that can expand scientific knowledge concerning the different aspects involved. Non-transmittable chronic diseases and aggravations have multifactor etiology and share various changeable risk factors, among which is inadequate diet, with distinction to insufficient intake of fruit, vegetables and legumes. Considering the importance of this food group to general health and to the reduction of non-transmittable chronic diseases and aggravations, the present study aimed at describing the intake of fruit, vegetables and legumes and at identifying the factors associated with such intake in an adult population of users of a public primary health care service. In order to describe the intake of fruit, vegetables and legumes, a 24-hour recall was used, and a method of adjustment for energetic intake was performed. A form specifically designed for the present study, guided by a theoretical model for determination of individual adults' dietary behavior, was used to collect socioeconomic and anthropometric data as well as information concerning the factors potentially associated with the intake of fruit, vegetables and legumes. The studied population predominantly consisted of poorly educated middleaged overweight women with a high prevalence of chronic diseases. The mean daily intake of fruit, vegetables and legumes, adjusted for energy, was equal to 281.3 grams, and the mean percentage of energy in the diet provided by this dietary group was equal to $8.7 \%$. Of the evaluated individuals, $40.9 \%$ reached the World Health Organization recommendation for minimum intake equal to $9 \%$ of the total energy in the diet. The intake of fruit, vegetables and legumes (in percentage of energy) was associated with gender, and the highest intake was observed among women; with nutritional status, the highest value being observed in overweight individuals; and with participation in individual nutritional 
care as compared to non-participants. In the studied population, a higher mean intake was observed as compared to that found for representative samples of the Brazilian population, which was possibly due to the older age and altered health conditions of the individuals, who used the health care service more frequently, were more exposed to nutritional approaches and more susceptible to dietary changes. It is concluded that actions are necessary in order to encourage the intake of this dietary group by younger, less educated, male users who do not participate in individual actions for dietary advice, which would require, in addition to the enhancement of strategies targeted at users, the development of actions targeted at the community.

Key words: dietary intake, fruit, vegetables and legumes, determinants, primary care. 


\section{Sumária}

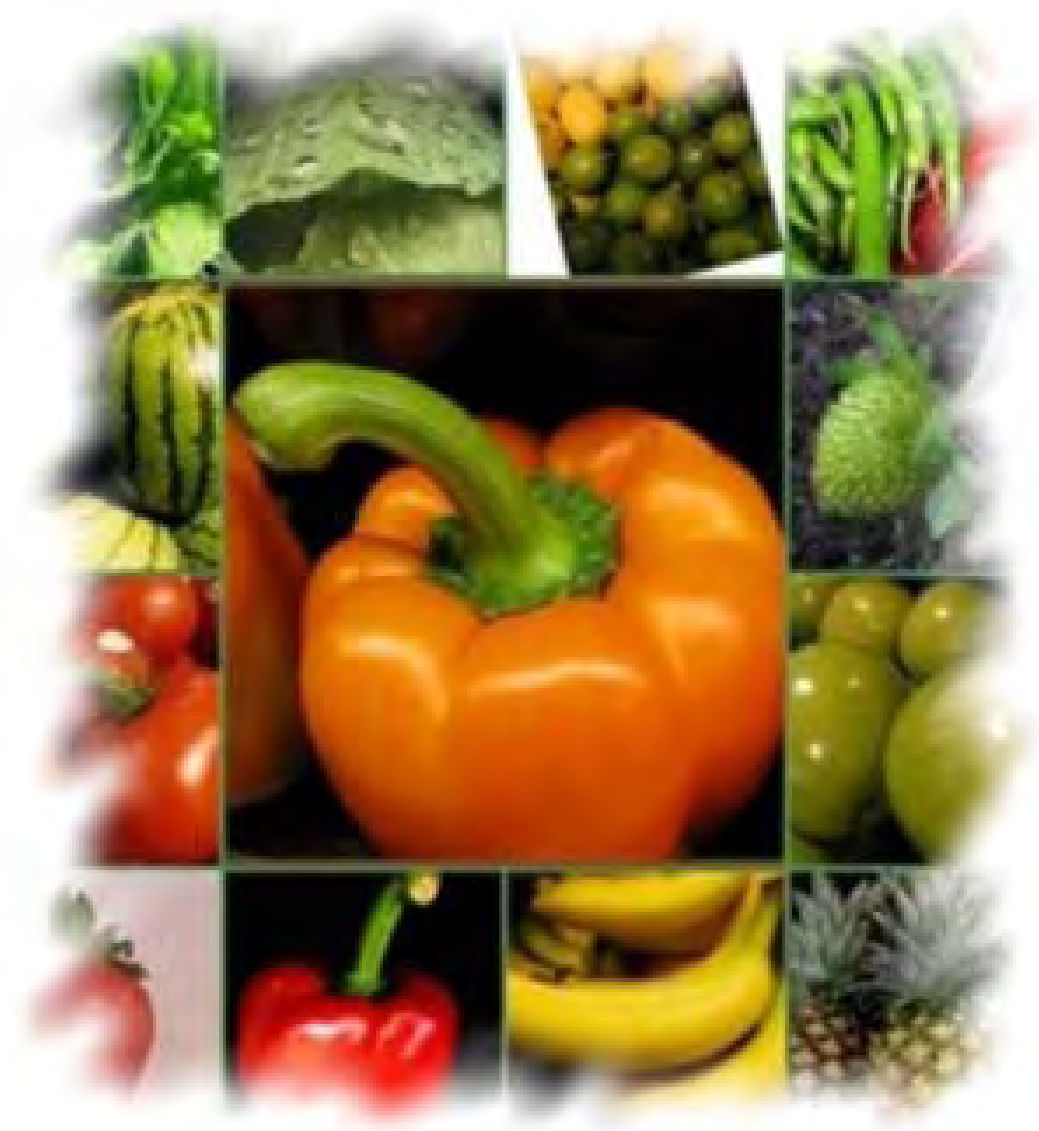


2. OBJETIVOS

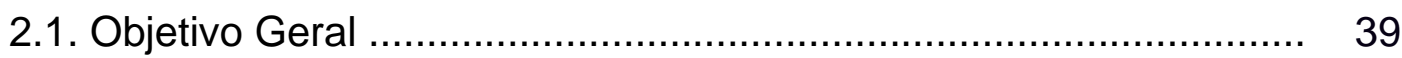

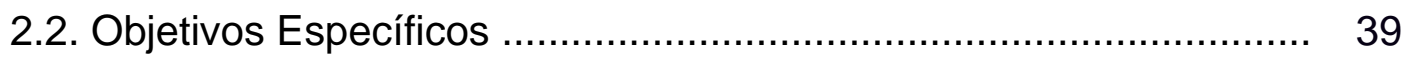

3. METODOLOGIA _ 40

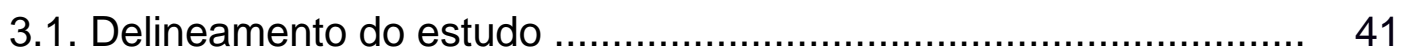

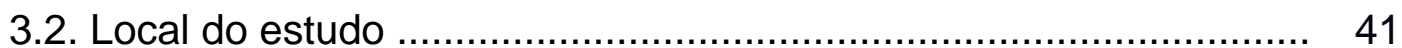

3.3 Modelo Teórico dos Determinantes do Consumo de Frutas, 44 Verduras e Legumes......................................................

3.4. População do estudo e amostra.......................................... 47

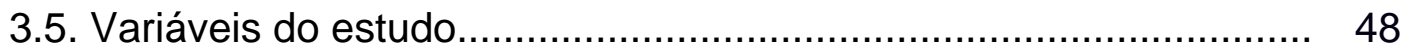

3.5.1. Variável dependente .............................................. 48

3.5.2. Variáveis independentes............................................ 48

3.6. Instrumentos e Coleta dos dados .................................... 49

3.7. Análise dos Dados .................................................... 51

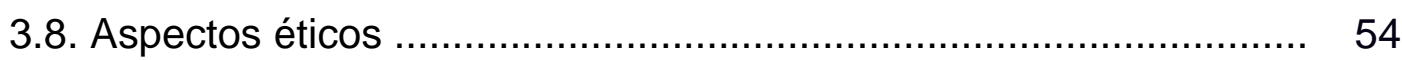

4. RESULTADOS $\quad 55$

4.1. Características da população .................................................. 56

5. DISCUSSÃO _ 76

6. CONCLUSÃO _ـ 85

REFERÊNCIAS _ 88

$\begin{array}{lr}\text { ANEXOS } & 94\end{array}$ 


\section{Intraduçãa}

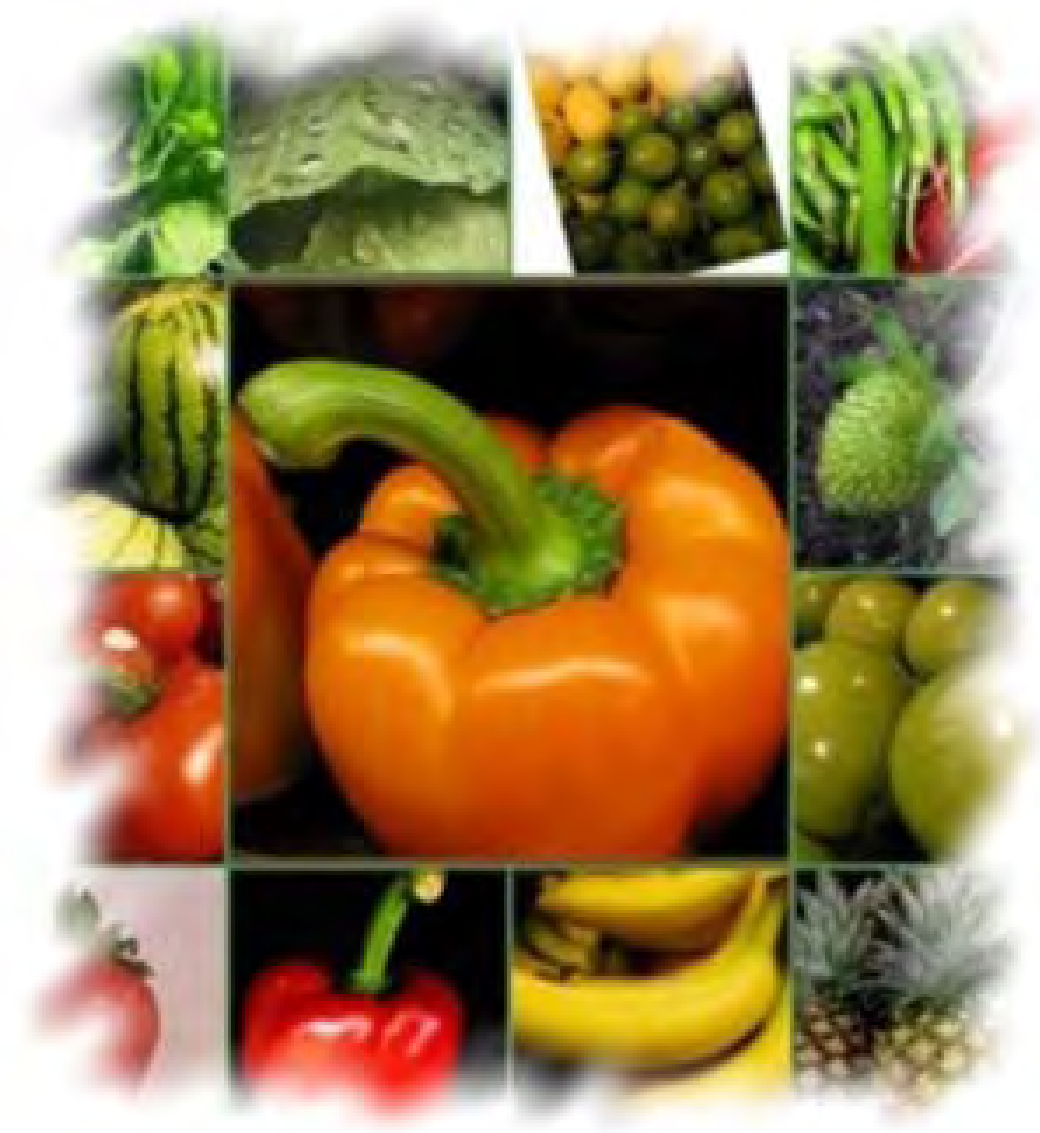


A alimentação inadequada e o consumo insuficiente de frutas, verduras e legumes ( $F r, V \& L)$ estão relacionadas à maior prevalência de doenças e agravos crônicos não transmissíveis (DANT), como diabetes, obesidade, doenças cardiovasculares e alguns tipos de cânceres. A complexidade dos determinantes relacionados a essa situação tem exigido o desenvolvimento de investigações que ampliem o conhecimento científico sobre os diferentes aspectos envolvidos. Nesse contexto, é crescente a importância dos estudos sobre o consumo de frutas, verduras e legumes e seu papel na prevenção e controle de muitas DANT.

As doenças e agravos crônicos não transmissíveis representam a principal causa de mortalidade e incapacidade no mundo inteiro. Afetam tanto as populações dos países desenvolvidos como as dos países em desenvolvimento e sua importância se explica por sua elevada prevalência e custo social. ${ }^{1}$

Estimativas da Organização Mundial de Saúde (OMS) mostram que as DANT são responsáveis por $60 \%$ de todas as mortes ocorridas no mundo, ou cerca de 35 milhões de mortes em 2005 (WHO 2005). No Brasil as DANT seguem padrão semelhante, e foram a principal causa de óbito em 2006, destacando-se as doenças do aparelho circulatório $(29,4 \%)$ e as neoplasias $(15,1 \%) .^{2}$

Tais agravos e doenças são de etiologia multifatorial e compartilham vários fatores de riscos modificáveis como o tabagismo, a alimentação inadequada, com destaque para a ingestão insuficiente de frutas, legumes e verduras, a obesidade, a dislipidemia (determinadas principalmente pelo consumo excessivo de gorduras saturadas de origem animal) e a inatividade física. $^{3}$

Especificamente quanto aos fatores alimentares, dados relativos ao consumo de alimentos e estado nutricional da população brasileira apontam situações complexas. A Pesquisa de Orçamento Familiar (POF) 2003, que analisou a disponibilidade domiciliar de alimentos adquiridos pelas famílias 
brasileiras, confirmou mudanças de padrão alimentar no país favoráveis à redução de problemas associados à desnutrição, como o aumento na disponibilidade de calorias per capita e da participação de alimentos de origem animal na alimentação. Por outro lado, apontou também aspectos muito negativos, desfavoráveis ao controle de doenças carenciais, como anemia e hipovitaminose $A$, da obesidade e demais DANT, com destaque para o aumento do consumo de gorduras em geral, de gorduras de origem animal e açúcar e a diminuição de cereais, leguminosas, frutas, verduras e legumes. Associadas ao sedentarismo, essas tendências podem explicar as altas taxas de sobrepeso e obesidade entre adultos brasileiros na atualidade. ${ }^{4}$

Inúmeros estudos afirmam que a alimentação rica em Fr,V\&L é fundamental a todo regime alimentar saudável e que pode contribuir para o controle das DANT atuando tanto nos mecanismos de prevenção primária, evitando o desenvolvimento dessas doenças e agravos, como na prevenção secundária, evitando suas complicações, especialmente em relação às doenças cardiovasculares e alguns tipos de cânceres, particularmente os do trato digestivo. Diversos mecanismos fisiológicos podem mediar esses efeitos protetores, envolvendo antioxidantes e micronutrientes, como os flavonóides, carotenóides, vitamina $\mathrm{C}$, folatos ${ }^{1}$. As frutas e as hortaliças têm assumido posição de destaque nos estudos que envolvem a prevenção do câncer. ${ }^{5}$

O "World Cancer Research Fund - WCRF" (Fundo Mundial para a Pesquisa em Câncer) em associação com o "American Institute for Cancer Research - AICR" (Instituto Americano para Pesquisa em Câncer) publicou em 1997 o documento "Alimentos, Nutrição e Prevenção de Câncer: uma perspectiva global". Este documento tornou-se referência em todo mundo para gestores em todos os níveis governamentais, para a sociedade civil, organizações de profissionais de saúde e centros de ensino e pesquisa de excelência acadêmica.

Em 2001 o WCRF Internacional em colaboração com o AICR iniciou um processo global para produzir e publicar um novo relatório, o que foi feito em 2007. O objetivo deste novo relatório foi examinar toda pesquisa pertinente, 
usando métodos mais meticulosos, para gerar uma série de recomendações sobre alimentos, nutrição e atividade física, voltadas para a redução do risco de câncer, adequadas a todas as sociedades. O relatório apresenta metas de saúde pública para as populações e profissionais de saúde, e recomendações para pessoas, comunidades, famílias e indivíduos, determinadas por um painel de especialistas. Dentre as recomendações, há destaque para o incentivo ao consumo de alimentos de origem vegetal: como meta de saúde pública, recomenda-se o consumo diário de hortaliças (sem amido) e de frutas de no mínimo 600g; como recomendação pessoal, o consumo de pelo menos 5 porções (no mínimo 400g) de hortaliças (sem amido) e de frutas de diferentes cores, como vermelha, verde, amarela, branca, roxa e laranja todos os dias. Esses alimentos protegem contra alguns cânceres, apresentam quantidades substanciais de fibras, grande variedade de micronutrientes, baixa densidade energética e são apontados como capazes de promover um peso saudável. As evidências mostram que a maior parte dos padrões alimentares que são protetores contra o câncer é constituída principalmente por alimentos de origem vegetal. No entanto, o painel de especialistas reconhece que, em cenários nacionais, as recomendações do relatório serão melhores utilizadas quando em conjunto com aquelas feitas pelos governos, para a prevenção de doenças crônicas e outras doenças. Os especialistas finalizam reforçando que as metas de saúde pública e recomendações pessoais feitas por eles são apresentadas como uma contribuição significativa dirigida à prevenção e controle do câncer em todo o mundo. ${ }^{6}$

O Instituto Nacional do Câncer (INCA), órgão do governo federal brasileiro, vinculado à Secretaria de Assistência à Saúde do Ministério da Saúde, é responsável pela formulação da Política Nacional de Controle do Câncer e pela implantação e coordenação de programas e iniciativas de melhoria da assistência médica, prevenção, controle e vigilância do câncer em todos os estados brasileiros. Esse órgão tem atuado como facilitador e fomentador da promoção das práticas alimentares saudáveis entre organizações não-governamentais, como também no desenvolvimento de políticas públicas que estimulem a alimentação saudável, incluindo o incentivo 
ao consumo de pelo menos cinco porções de frutas, legumes e verduras variados ao dia. ${ }^{7,8}$

A estratégia global em alimentação saudável, atividade física e saúde, apresentada pela Organização Mundial da Saúde (OMS) na 57a Assembléia Mundial de Saúde em 2004, representa outra importante iniciativa global que apresenta como uma de suas metas a promoção da consciência e do conhecimento geral acerca da influência da alimentação saudável e da atividade física em saúde. O Ministério da Saúde brasileiro acompanhou o processo de formulação dessa estratégia, adotando-a por meio do desenvolvimento de ações para incentivar a promoção de modos de vida saudável, prevenção e controle das DANT. Uma das ações foi a elaboração do Guia Alimentar para a População Brasileira (Brasil, 2005), que estabeleceu diretrizes com o objetivo de incentivar as práticas alimentares saudáveis e a promoção da saúde. Uma das diretrizes, a de número 3, apresenta recomendações relacionadas ao consumo de frutas, verduras e legumes, com o incentivo ao consumo diário de três porções ou mais de frutas e três porções de legumes e verduras, valorizando a utilização dos alimentos regionais e os alimentos de estação (sazonalidade). Vale mencionar que os alimentos vegetais como os tubérculos e raízes ricos em carboidratos e as leguminosas ricas em proteínas, não estão incluídos no grupo denominado "Frutas, Verduras e Legumes" mencionados na Diretriz $3 .^{9}$

O programa "5 a Day", iniciado nos Estados Unidos da América em 1991, tem como objetivo a promoção do consumo diário de pelo menos cinco porções de frutas, legumes e verduras, a fim de contribuir para a prevenção de diversas doenças crônicas associadas à alimentação. ${ }^{10}$ Esta estratégia de promoção do consumo de frutas, legumes e verduras está presente atualmente em mais de 30 países, sendo reconhecida mundialmente. No Brasil, este programa tem sido difundido pelo Instituto Brasileiro de Orientação Alimentar (IBRA), que tem adotado como estratégia a sensibilização da população para a importância da alimentação saudável por meio de palestras, produção e distribuição de materiais informativos para apoio de campanhas promocionais, 
eventos e seminários desenvolvidos em empresas, entidades de classe, escolas, redes de comércio varejista de alimentos e outras instituições. ${ }^{11}$

Embora a preocupação com o monitoramento do consumo de frutas, verduras e legumes pela população brasileira seja crescente entre pesquisadores e instituições de saúde, sua tradução em políticas de atuação que consigam alterar o consumo desse grupo alimentar ainda são incipientes.

$\mathrm{Na}$ análise realizada pela Pesquisa de Orçamento Familiar (POF) de 2003, para um consumo calórico médio de 1800 calorias, a participação deste grupo foi de $3,37 \%$ do total energético, com uma participação absoluta em torno de 60 calorias e 132 gramas.

Segundo a recomendação da OMS, de consumo diário de pelo menos 400 gramas de frutas, legumes e verduras frescos ou o equivalente a cinco porções desses alimentos, é necessário que, por exemplo, em uma dieta de 2000 calorias, 9\% das calorias totais (183 calorias) sejam provenientes deste grupo de alimentos, apontando que o consumo brasileiro encontra-se muito distante do preconizado. ${ }^{3}$

Levy-Costa et al (2005) ${ }^{12}$ realizaram um estudo sobre a distribuição e evolução da disponibilidade domiciliar de alimentos no Brasil entre os anos de 1974 e 2003. Os autores tomaram como a principal base de dados do estudo os resultados da Pesquisa de Orçamento Familiar de 2002 - 2003, realizada pelo Instituto Brasileiro de Geografia e Estatística em 48.470 domicílios brasileiros. Em cada domicílio foram registradas todas as aquisições, monetárias e não monetárias de alimentos e bebidas para o consumo familiar, por um período de sete dias consecutivos. As quantidades dos alimentos adquiridos foram transformadas em calorias e macronutrientes e calculada a participação relativa na disponibilidade alimentar a partir do percentual de calorias que o alimento representava no total de calorias disponíveis para consumo. O estudo verificou que a participação de frutas e hortaliças correspondia a cerca de um terço das recomendações para o consumo desses alimentos. 
Jaime \& Monteiro (2005) ${ }^{13}$ realizaram o primeiro estudo nacional com a intenção de avaliar o consumo individual de frutas e hortaliças no Brasil, através dos dados da "World Health Survey - WHS" (Inquérito sobre a Saúde Mundial) realizado no Brasil em 2003. O estudo estimou a freqüência e distribuição do consumo de frutas e hortaliças e analisou a influência das variáveis demográficas e sócio-econômicas na determinação dos padrões de consumo para esses alimentos na população adulta brasileira. O consumo individual de frutas e hortaliças foi investigado com base em quatro questões: "Em geral, quantas vezes por semana você consome frutas?", "Quantas porções de frutas você normalmente consome por dia?", "Em geral, quantas vezes por semana você consome hortaliças (como alface, espinafre, tomate, cenoura, vagem etc.)?", e "Quantas porções de hortaliças ou vegetais você normalmente consome por dia?". Foram obtidos os seguintes resultados: menos da metade (41\%) dos indivíduos consumiam hortaliças diariamente; menos de um terço (30\%) relatavam consumo de frutas diariamente; apenas um em cada cinco indivíduos relatava o consumo de frutas e hortaliças todo o dia; apenas um em cada oito seguia a recomendação de consumir cinco ou mais porções de frutas e hortaliças por dia. O estudo apontou também que o aumento da escolaridade e a disponibilidade de bens domésticos apresentaram associação com o consumo de frutas e hortaliças.

Moura et al $(2008)^{14}$ investigaram os fatores de risco para doenças crônicas através de inquérito telefônico nas capitais dos 26 estados brasileiros e no Distrito Federal. Observaram que a freqüência de indivíduos que consomem regularmente frutas e hortaliças em cinco ou mais dias da semana foi de $23,9 \%$ no conjunto da população adulta das 27 cidades avaliadas. Em todas as cidades, o consumo regular de frutas e hortaliças foi mais freqüente em mulheres do que em homens.

Em estudo também recente, Figueiredo et al $(2008)^{15}$ analisaram os fatores associados ao consumo de frutas, legumes e verduras em população adulta da cidade de São Paulo, através de entrevistas telefônicas, num total de 1267 mulheres e 855 homens. O consumo de frutas, verduras e legumes foi 
avaliado por um escore de freqüência com perguntas curtas e simples. Para avaliar os fatores associados ao consumo de frutas, legumes e verduras as variáveis estudadas foram agrupadas em blocos, sendo no primeiro bloco as variáveis sócio-demográficas, no segundo as características comportamentais e no terceiro as variáveis relacionadas ao padrão alimentar. Observaram que o consumo diário de frutas foi maior entre as mulheres do que entre os homens (51,7\% vs $35,0 \%)$ e que o consumo diário de legumes foi duas vezes maior entre as mulheres do que entre os homens $(p<0,001)$. O escore de freqüência de consumo de frutas, legumes e verduras variou de zero a três, apresentando média de 1,67 para ambos os sexos, 1,82 para as mulheres e 1,50 para os homens. Os fatores sócio-demográficos que mostraram correlação significante com o consumo de frutas, legumes e verduras foram o aumento da idade $(p<0,001)$ e a maior escolaridade $(p<0,001)$ para ambos os sexos, ou seja, a maior freqüência do consumo desses alimentos ocorreu entre os indivíduos mais velhos e entre aqueles que possuíam maior escolaridade.

Jorge et al (2008) ${ }^{16}$ analisaram o consumo de frutas, verduras e legumes em mulheres residentes no município de Cotia, região metropolitana de São Paulo, segundo fatores sócio-demográficos, econômicos e comportamentais. Observaram maior risco de baixo consumo de frutas nas mulheres de bairro pobre, com baixa escolaridade, baixa renda familiar e tabagistas. Os diferenciais de consumo de verduras foram associados mais à cultura alimentar do que à pobreza, enquanto os de legumes foram relacionados tanto ao nível socioeconômico quanto à cultura alimentar, sendo pouco consumidos pelas mulheres mais jovens, com pouca escolaridade e renda familiar. Em conjunto, o consumo de frutas, verduras e legumes apresentaram diferenciais relacionados ao nível socioeconômico, à cultura alimentar e aos hábitos comportamentais.

No município de Botucatu, cidade de médio porte do interior do estado de São Paulo e local onde o presente estudo foi realizado, Fisberg et al $(2004)^{17}$ avaliaram o índice de qualidade da dieta (IQD) em amostra representativa da população. O IQD foi obtido por uma pontuação distribuída 
em dez componentes que caracterizavam diferentes aspectos de uma dieta saudável. O consumo alimentar foi medido através do método recordatório de 24 horas. Observaram baixa ingestão de frutas e vegetais (consumo menor que cinco porções diárias) e alta ingestão de gorduras nos indivíduos avaliados. 0 IQD médio foi de 51,5\%, dos indivíduos avaliados, 12\% apresentaram dieta saudável, 74\% dieta que necessita de modificação e 14\% dieta inadequada.

Posteriormente, Carvalhaes et al $(2004)^{18}$, em inquérito telefônico metodologicamente equivalente ao realizado na cidade de São Paulo ${ }^{15}$, observaram taxas insatisfatórias de consumo regular deste grupo alimentar. Constataram que o consumo de frutas, hortaliças cruas e cozidas medido com a frequência de cinco ou mais dias da semana foi superior que entre as mulheres do que ao observado em homens: frutas (52,3\% versus 48,6\%), hortaliças cruas $(81,4 \%$ versus $76,6 \%)$ e hortaliças cozidas $(61,8 \%$ versus $56,8 \%)$.

Em outro estudo realizado em Botucatu, Bonard (2009) ${ }^{19}$ descreveu a dieta e pesquisou determinantes da qualidade alimentar de adultos e idosos atendidos em uma Unidade de Saúde da Família, num total de 255 indivíduos. Foi utilizado um questionário de avaliação desenvolvido para a pesquisa, que incluiu questões sobre avaliação clínica e nutricional, fatores comportamentais, características sócio-econômicas e demográficas. Para avaliar os hábitos alimentares utilizou-se o recordatório de 24 horas, um questionário qualitativo de freqüência alimentar e o índice de alimentação saudável adaptado. Os resultados mostraram um consumo médio diário de $117,5 \mathrm{~g}$ de frutas e de $84,6 \mathrm{~g}$ de hortaliças, sendo que $85,8 \%$ da população do estudo ficaram abaixo da recomendação da ingestão diária de $400 \mathrm{~g}$ de frutas e hortaliças, sem diferenças entre sexos ou faixa etária.

Os dados de literatura até aqui comentados apontam um consumo distante dos recomendados nos diferentes universos estudados. Em sua maioria de base populacional, ainda que usando diferentes metodologias de avaliação, os trabalhos apresentados nos colocam como questão mais ampla o 
desafio de desenvolver estratégias de intervenção que alterem os padrões observados em direção a alimentação mais saudável.

Nesse sentido, o estudo de grupos populacionais bem delimitados e já submetidos a ações de assistência e orientação nutricional pode contribuir para o aprimoramento de ações realizadas no âmbito da atenção primária que possam se voltar tanto para os usuários em seguimento nas unidades como para a população em geral residente nas áreas de responsabilidade de cada serviço. A pertinência de estudos locais se justifica ainda pela imensa diversidade cultural e socioeconômica das diversas regiões de nosso país e no interior de cada uma delas.

Essas questões orientaram a avaliação do consumo de frutas, verduras e legumes em uma unidade de atenção primária onde já se desenvolvem diferentes ações de orientação nutricional voltadas aos usuários. A caracterização do consumo nessas particulares condições representa uma etapa preliminar necessária para o aprimoramento de programas de intervenção em Unidades Básicas de Saúde que possam ser dirigidas ao conjunto da população residente em suas áreas de cobertura e que levem em conta as condições concretas de vida em cada região. 
2. Clijetinas

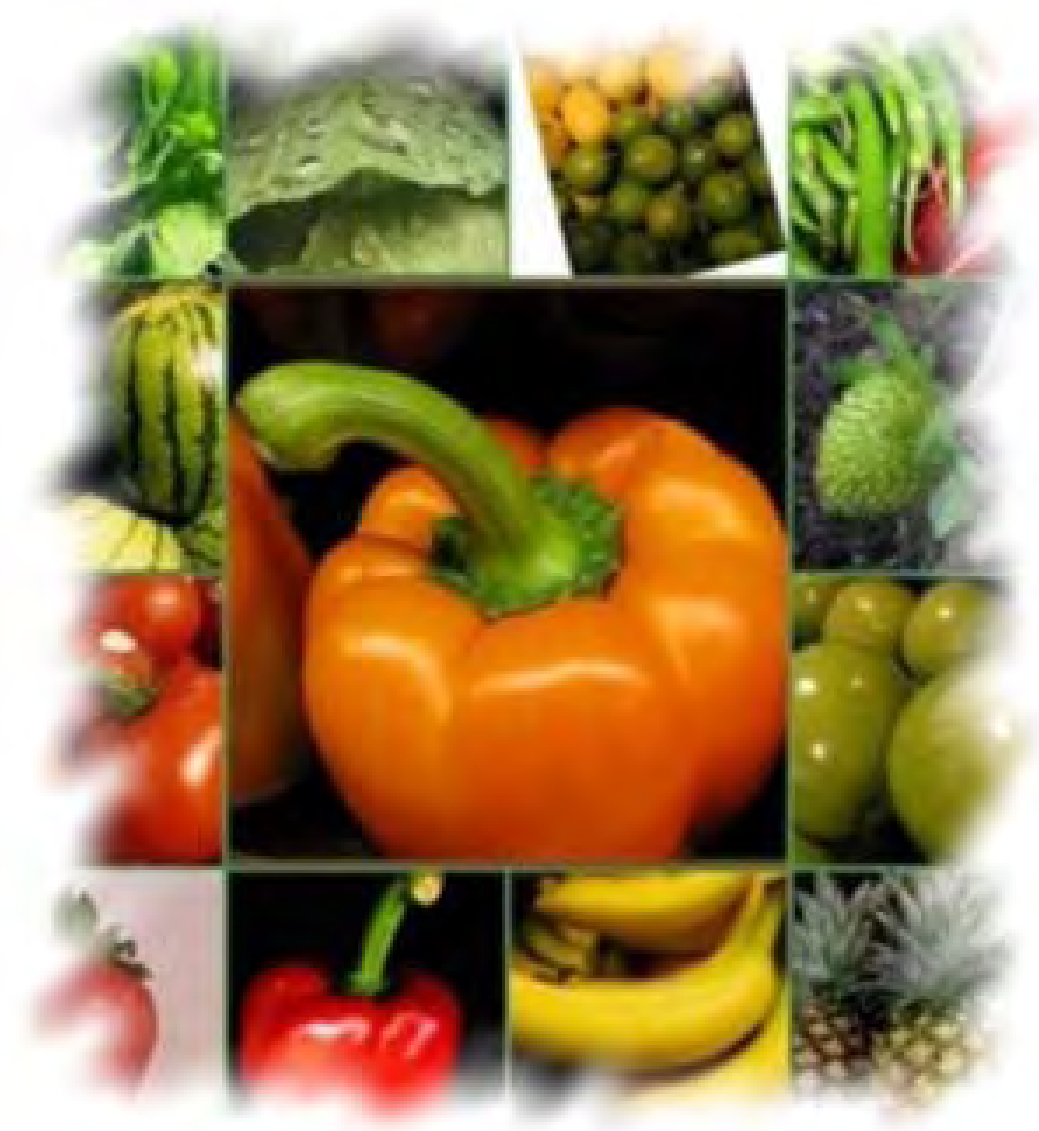




\subsection{Objetivo Geral}

Descrever o consumo de frutas, verduras e legumes (Fr,V\&L) e identificar fatores associados em população adulta assistida em serviço de atenção primária à saúde de município do interior paulista.

\subsection{Objetivos Específicos}

1- Identificar os alimentos do grupo de Fr,V\&L consumidos e ordená-los por ordem decrescente de consumo;

2- Estimar o consumo médio de Fr,V\&L, em gramas e em porcentagem de energia total consumida;

3- Verificar a proporção dos indivíduos que alcançam e não alcançam a recomendação do consumo de $\mathrm{Fr}, \mathrm{V} \& \mathrm{~L}$, em gramas e em porcentagem de energia total consumida;

4- Identificar a associação entre consumo de Fr,V\&L e os seguintes fatores: socioeconômico, demográficos e nutricionais, condições de saúde e participação em atendimento nutricional em Unidade Básica de Saúde. 


\section{Metadalagia}

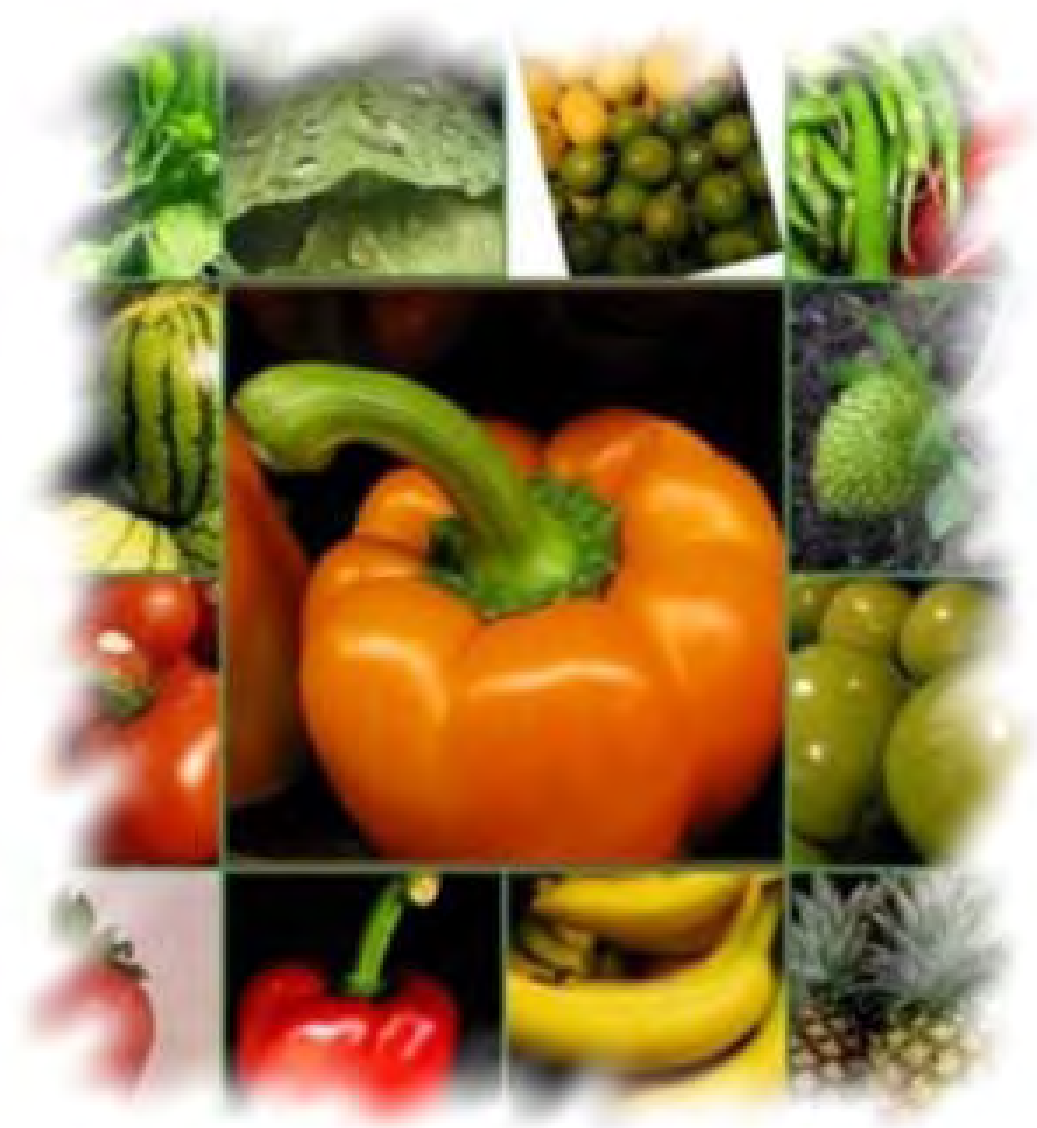




\subsection{Delineamento do estudo}

Trata-se de estudo transversal, analítico, no qual é descrito e avaliado o consumo atual de frutas, verduras e legumes de uma população adulta usuária de serviço público de atenção primária à saúde, investigando-se os fatores potencialmente associados a esse consumo.

\subsection{Local do estudo}

O estudo foi realizado no Centro de Saúde Escola (CSE) da Faculdade de Medicina de Botucatu (FMB), criado em 1972 e dirigido, desde então, pelo Departamento de Saúde Pública. Nestas três décadas, o CSE passou por diferentes mudanças nas atividades desenvolvidas, bem como na sua área física, nos recursos humanos e materiais disponíveis. ${ }^{20}$ Hoje, é uma Unidade Auxiliar de Estrutura Complexa de Saúde Escola subordinada à FMB, com administração própria, tendo como missão: assistência, ensino e pesquisa na Atenção Primária. O CSE caracteriza-se assim como uma unidade que tem por finalidade investigar e desenvolver novas alternativas de intervenção nesse nível de atenção à saúde. Segundo definição elaborada pela própria equipe do CSE, Atenção Primária é:

\footnotetext{
Conjunto de ações e atividades desenvolvidas, mediante a articulação de saberes de diversos profissionais e diferentes modalidades de atendimento, com vistas a impactar positivamente na saúde e qualidade de vida dos indivíduos e das comunidades, com base nos princípios da universalidade, eqüidade, integralidade, intersetorialidade, participação social, privilegiando-se as ações de caráter preventivo e valorizando-se o auto-cuidado. É uma das "portas de entrada" do sistema, que deve alcançar alto grau de resolutividade dos problemas de saúde da população. Desenvolve-se de forma dinâmica, caracterizando-se como um processo de cuidado em saúde, sendo uma estratégia de reorganização de todo o sistema de saúde. (CSE, 2007)
} 
Com base nessa concepção, além das ações de assistência direta, a unidade fornece apoio técnico à rede básica do município em diversas áreas, como: tabagismo, tuberculose, hanseníase, testagem e aconselhamento em doenças sexualmente transmissíveis e síndrome da imunodeficiência adquirida (DST/AIDS) e saúde mental. Realiza capacitação de recursos humanos em saúde pública e em atenção primária à saúde para a rede básica e é campo de estágio de alunos de graduação em Medicina, Enfermagem e Nutrição e de alunos de pós-graduação (aprimoramento, residência e especialização).

No campo da assistência desenvolve atividades nas áreas de Saúde do Adulto, da Mulher, Criança e Saúde Mental, para uma área de cobertura com um total de 30.000 habitantes. Na Área da Saúde do Adulto, as maiores demandas são pacientes idosos, pessoas com sobrepeso, obesidade grau I, diabéticos e hipertensos. ${ }^{20}$

A equipe de trabalho é composta por 86 profissionais de diversas categorias: médicos, enfermeiros, psicólogos, assistentes sociais, dentistas, nutricionistas, terapeuta ocupacional, fisioterapeuta, fonoaudióloga, técnicos de enfermagem e administrativos, entre outros. Docentes de vários departamentos da FMB, também compõem o corpo assistencial do serviço. Os profissionais atuam em diferentes modalidades de atendimento: consultas individuais, grupos terapêuticos, atividades de educação em saúde, busca ativa, vigilância em saúde, visitas domiciliares, atividades educativas em sala de espera, aconselhamento, coleta de exames, vacinação, pequenos procedimentos cirúrgicos, procedimentos odontológicos, entre outros.

Atividades do campo da Nutrição estão presentes nas quatro grandes áreas de assistência (Saúde Adulto, Mulher, Criança e Saúde Mental), com diferentes formas de abordagem: atendimento nutricional individual (ANI), atividade educativa em grupo (AEG) e atividade educativa em sala de espera (AESE).

Na área da Saúde do Adulto, o ANI é realizado por nutricionistas, aprimorandos e alunos do curso de nutrição em estágio curricular de Saúde 
Pública, sob supervisão do profissional responsável da unidade, assim como, por médico nutrólogo. É direcionado a pessoas com sobrepeso, obesidade grau I, II e III, diabéticos, hipertensos, dislipidêmicos, entre outras morbidades.

As AEG realizadas na área da Saúde do Adulto são: grupo de dislipidemia e hipertensão coordenadas pelo profissional nutricionista, grupo de diabetes coordenado por equipe multiprofissional e grupo de obesidade coordenado por nutrólogo e/ou aprimorando nutricionista.

As AESE possuem caráter educativo, tem como objetivo aproveitar o tempo de espera dos pacientes, enquanto aguardam sua consulta, fornecendo informações e orientações relacionadas à alimentação. São realizadas por meio de didática apropriada com informações dispostas em painéis informativos e/ou álbuns seriados, folhetos com reforço das informações obtidas e, em alguns momentos, degustação de alimentos e/ou preparações, com intenção de trabalhar o paladar e as práticas culinárias. São abordados assuntos sobre bons hábitos alimentares e estilo de vida que despertem a atenção de todos e incentivem a realização de práticas saudáveis. Além disso, as AESE constituem-se como um espaço para que eventuais dúvidas e "mitos" sobre os assuntos apresentados e questões alimentares em geral possam ser esclarecidos. Essas atividades são realizadas periodicamente por alunos do curso de Nutrição em estágio curricular de Saúde Pública e são supervisionadas por nutricionista da Unidade. Após a atividade, os painéis informativos são mantidos expostos nas áreas, com intenção de chamar a atenção de um maior número de pessoas.

As atividades nutricionais mencionadas - ANI e AEG - são realizadas nas áreas da Saúde do adulto, Saúde da criança e Saúde da mulher; as AESE são realizadas em todas as salas de espera da Unidade, de modo a atingir em diferentes momentos o conjunto da população atendida. 


\subsection{Modelo Teórico dos Determinantes do Consumo de Frutas, Verduras e Legumes}

A identificação dos potenciais fatores associados ao consumo de Fr,V\&L foi guiada por um modelo teórico de determinação do comportamento alimentar de indivíduos adultos (M.T.D., Figura 1), construído com base na literatura (Toral\&Slater $^{21}$, Rossi et al $^{22}$, Barreto\&Figueiredo ${ }^{23}$ ) e em hipóteses levantadas pela autora da pesquisa, a partir de sua prática assistencial na referida Unidade de Saúde.

A partir deste M.T.D. foi desenvolvido um modelo simplificado para análise de fatores associados ao consumo de frutas, verduras e legumes (Figura 2) em adultos, contemplando cinco das dimensões reconhecidas em suas múltiplas determinações:

- socioeconômica, indicada pela escolaridade;

- sócio-demográfica, indicada pelo sexo e idade;

- características nutricionais, indicada pelo Índice de Massa Corpórea;

- características de saúde, indicada pelas DANT diagnosticadas;

- uso de serviços de saúde, indicado pela participação no ano anterior em atendimentos nutricionais individual e em atividade educativa em grupo.

As dimensões culturais, familiares e psicocognitivas não foram contempladas nesse estudo, por exigirem abordagens qualitativas, não utilizadas nessa investigação. 


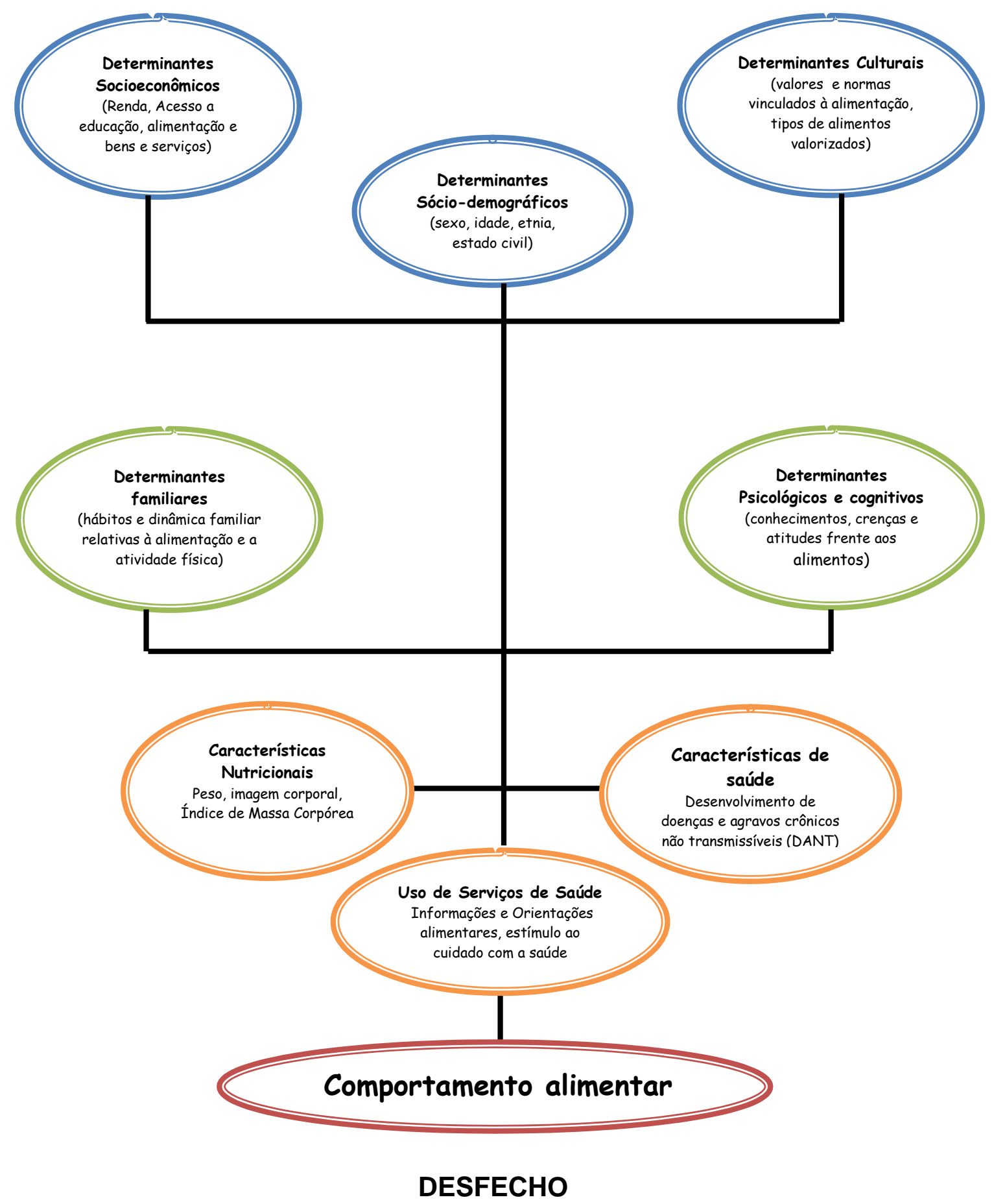

Figura 1 - Modelo teórico de determinação do comportamento alimentar no adulto (M.T.D.). 


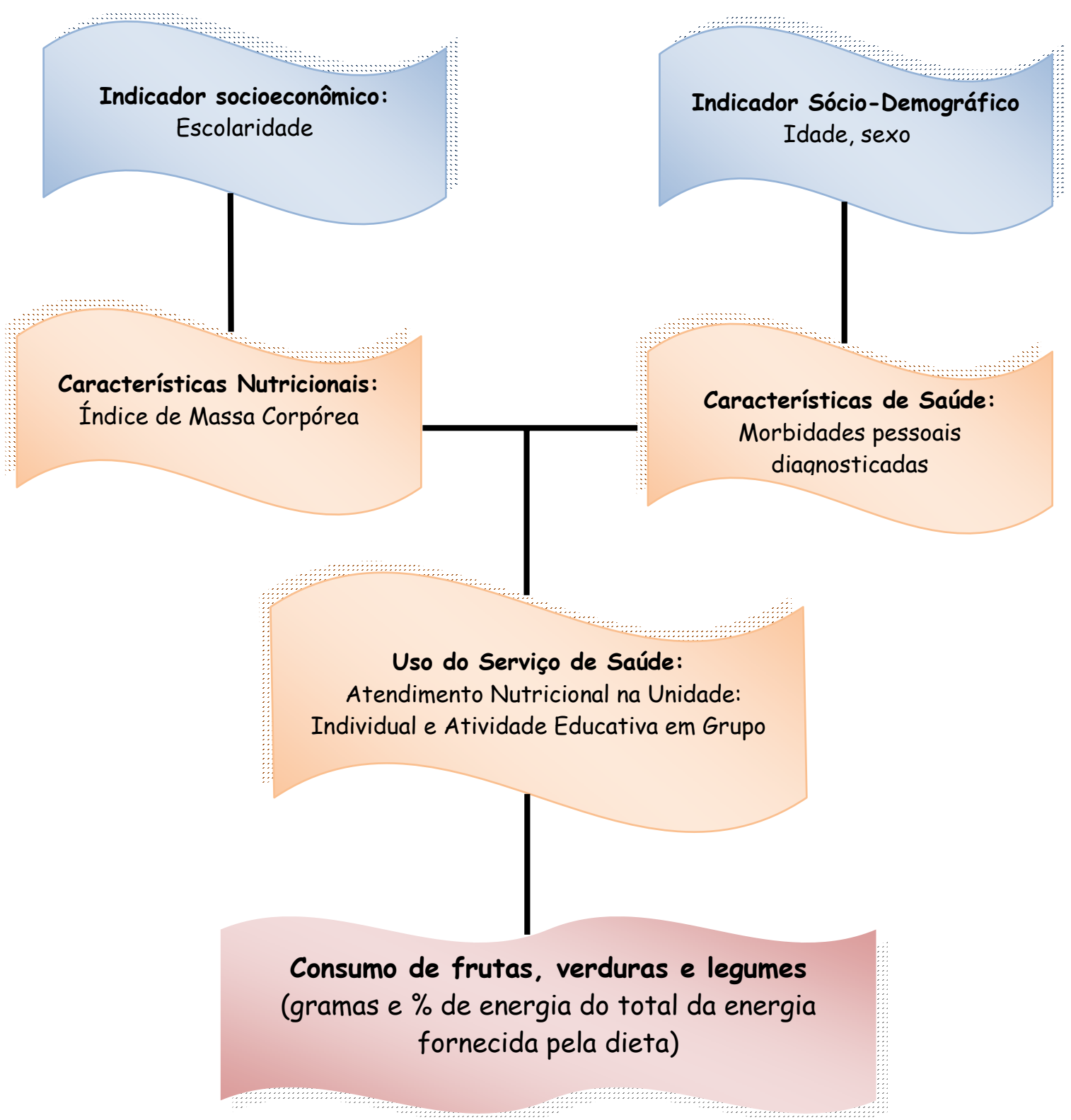

\section{DESFECHO}

Figura 2- Modelo de análise do consumo de frutas, verduras e legumes em adultos usuários de uma de Unidade de Saúde. 


\subsection{População do estudo e amostra}

A população da pesquisa correspondeu a homens e mulheres com idade maior ou igual a 18 anos que compareceram para consultas agendadas com diferentes profissionais na Área da Saúde do Adulto, no período entre 10/04 e 15/05/2007.

Estudou-se uma amostra de conveniência, inicialmente formada por 200 usuários. Foram entrevistados diariamente 8 a 12 usuários em seguimento que compareceram para atendimentos agendados e que concordaram em participar do estudo, de uma média de 65 pacientes agendados por período. O número máximo de entrevistados por dia foi limitado pela dinâmica e fluxo de atendimento de modo a não prejudicar a rotina da assistência na Área da Saúde do Adulto do CSE.

Do total de 200 pacientes inicialmente abordados foram excluídos 19 usuários, sendo 16 pela falta de informações suficientes em prontuário, 01 usuário por apresentar índice de massa corpórea $\geq 64,0 \mathrm{Kg} / \mathrm{m}^{2}, 02$ usuários por apresentarem ingestão calórica abaixo de 500 calorias ou acima de 5000 calorias. Esse último critério de exclusão tomou como limites a ingestão calórica diária entre 500 e 5000 calorias, valores definidos a partir a média da ingestão calórica total, menos três desvios padrões para baixo e para cima, com a intenção de minimizar os erros possíveis de informação da ingestão de R24h, que poderiam levar a subestimação ou superestimação dos nutrientes, como sugerem Nielsen \& Adair $^{24}$ em estudo sobre critérios de exclusões de dados dietéticos. 


\subsection{Variáveis do estudo}

\subsubsection{Variável dependente}

A variável desfecho deste estudo é o consumo diário de frutas, verduras e legumes, em gramas e em porcentagem da energia total consumida.

\subsubsection{Variáveis independentes}

\section{o Socioeconômica}

Escolaridade, em anos completos: 0 a 3 anos, 4 a 7 anos, 8 a 11 anos e maior igual a 12 anos.

\section{o Sócio-demográficas e Nutricional}

Idade, em anos: menor 60 anos, maior igual 60 anos

Sexo: feminino, masculino

Índice de Massa Corpórea (IMC), kg/m², categorizado segundo as recomendações do manual de técnicas e orientação da Vigilância Alimentar e Nutricional - SISVAN ${ }^{25}$

- Morbidades pessoais diagnosticadas

diabetes, hipertensão arterial, doença cardiovascular (DCV), dislipidemia, intolerância a glicose, hipotireoidismo, outras morbidades, sim, não 


\section{o Atendimento Nutricional}

Atendimento nutricional individual (ANI) no último ano (maio de 2006 a maio de 2007) - sim ou não

Atividade educativa em grupo (AEG) no último ano (maio de 2006 a maio de 2007) - sim ou não

\subsection{Instrumentos e Coleta dos dados}

O consumo de Fr,V\&L foi investigado mediante um recordatório alimentar de 24 horas (R24h) - Anexo 1. Este método permite conhecer a dieta atual e estimar valores absolutos ou relativos da ingestão de energia e nutrientes amplamente distribuídos no total dos alimentos consumidos por uma população. $^{26}$ Para melhor avaliação do consumo alguns cuidados são recomendados, como a realização de entrevistas em variados dias da semana e a utilização de técnicas facilitadoras da estimativa das porções consumidas.

As entrevistas aconteceram de segunda-feira a sexta-feira, sendo: $24,6 \%$ na segunda-feira, $15,1 \%$ na terça-feira, 23,6\% na quarta-feira, 22,6\% na quinta-feira e 14,1\% na sexta-feira, no período da manhã e da tarde, com exceção das terças-feiras e sextas-feiras à tarde. Foram realizadas por entrevistadora previamente treinada, nutricionista. Contou com a utilização de material de apoio, como mostruário de utensílios (copos pequeno e grande, xícaras de chá e café, caneca, colheres de servir, sopa, sobremesa, chá e café, escumadeiras pequena, média e grande, conchas pequena, média e grande, garfo para massa, entre outros adquiridos no comércio local) para uma adequada quantificação dos alimentos consumidos. Para os cálculos de quantidades em gramas de alimentos e quantificação da energia consumida foi utilizado o Programa de Apoio à Nutrição - NutWin, da Unifesp. Alimentos e preparações que não se encontravam no programa foram acrescentados através das tabelas de composição de alimentos - Suporte para Decisão 
Nutricional ${ }^{27}$, Tabela para a Avaliação de Consumo Alimentar e Medidas Caseiras ${ }^{28}$ e Tabela Brasileira de Composição de Alimentos - TACO, Versão $2^{29}$.

Para a obtenção das informações socioeconômicas, demográficas, nutricionais e sobre os fatores potencialmente associados ao consumo de Fr,V\&L, foi utilizado um formulário, construído para o presente estudo - anexo 2. Os dados foram coletados dos prontuários dos usuários após a data da entrevista dos R24h, utilizando o período das datas das entrevistas (10/04 a 15/05/2007) como referência para coleta dos dados.

A antropometria foi realizada pela equipe de enfermagem da área da saúde do adulto, a qual é capacitada para esta atividade. O peso foi medido em kg através de balança digital da marca Filizola com graduação de 0,1 kg, com capacidade de $150 \mathrm{~kg}$ e a altura foi medida através de antropômetro em forma de haste acoplado na mesma balança, conforme técnicas preconizadas pelo manual de técnicas e orientação da Vigilância Alimentar e Nutricional SISVAN. ${ }^{25}$

Para o diagnóstico nutricional da população estudada, foi utilizado o Índice de Massa Corpórea (IMC), sendo analisado segundo as recomendações do SISVAN (Quadro1).

Quadro 1 - Pontos de Corte para o Índice de Massa Corpórea - kg/m²

\begin{tabular}{|lll|}
\hline & Adulto ( $\leq 30$ a 59 anos) & Idoso ( $\geq 60$ anos) \\
\hline \hline Baixo peso & IMC menor $18,5 \mathrm{~kg} / \mathrm{m}^{2}$ & IMC igual ou menor $22,0 \mathrm{~kg} / \mathrm{m}^{2}$ \\
Eutrofia & IMC entre $\mathbf{1 8 , 5}$ e $24,9 \mathrm{~kg} / \mathrm{m}^{2}$ & IMC entre 22,1 e $26,9 \mathrm{~kg} / \mathrm{m}^{2}$ \\
Sobrepeso & IMC entre 25,0 e $29,9 \mathrm{~kg} / \mathrm{m}^{2}$ & IMC igual ou maior $27,0 \mathrm{~kg} / \mathrm{m}^{2}$ \\
Obesidade & IMC igual ou maior $30,0 \mathrm{~kg} / \mathrm{m}^{2}$ & \\
\hline
\end{tabular}




\subsection{Análise dos Dados}

Foi construído um primeiro banco de dados, com os cálculos dos R24h $(\mathrm{N}=200)$, através da exportação dos dados do Programa de Apoio à Nutrição NutWin para o programa Microsoft Excel 2007, com todos os alimentos ingeridos, quantidades e nutrientes consumidos. A partir deste banco primário, elaborou-se outro arquivo, através do Programa Statistical Analysis System (SAS), mantendo somente as variáveis de interesse (alimentos consumidos, quantidades em gramas dos alimentos, Energia).

Foi realizado o método de ajuste energético - residual, para o consumo de Fr,V\&L em gramas, pois ele permite a obtenção do dado líquido, sem influência da energia consumida. Neste caso o nutriente residual foi o consumo de $\mathrm{Fr}, \mathrm{V} \& \mathrm{~L}$ ajustado pela energia calculada acrescentando-se o resíduo de um modelo de regressão linear simples, tendo como variável independente o total de energia ingerida e como variável dependente o consumo de Fr,V\&L. Para estimar o valor residual de Fr,V\&L, determinou-se a quantidade em gramas de Fr,V\&L que cada indivíduo consumiu, com a sua média de energia consumida, utilizando-se a seguinte equação: $Y_{c}=\beta_{0}+\beta_{1} \times$ média energia, onde: $Y_{c}=$ valor de correção, $\beta_{0}=$ intercept, $\beta_{1=}$ energia, para cada sexo. O ajuste do consumo dos nutrientes pela energia é uma etapa metodológica fundamental no refinamento da análise dos dados dietéticos e na interpretação dos achados em epidemiologia nutricional. ${ }^{30}$

Um segundo banco de dados foi elaborado, com os itens do consumo de Fr,V\&L em gramas bruto e ajustado, energia de Fr,V\&L em Calorias, porcentagem de energia de $\mathrm{Fr}, \mathrm{V} \& \mathrm{~L}$ da dieta e a energia total da dieta, acrescido dos itens do formulário das variáveis independentes ( $n=181)$, no programa Microsoft Excel 2007. E a partir deste, elaborou-se outro arquivo, através do Programa Statistical Analysis System (SAS).

Um terceiro banco de dados foi realizado com os alimentos consumidos do grupo alimentar de frutas, verduras e legumes $(n=181)$, no programa 
Microsoft Excel 2007. A partir deste, foi elaborada uma lista em ordem decrescente de contribuição percentual dos alimentos em porcentagem de energia e em gramas, como o método proposto por Block et al, utilizando-se a seguinte equação:

$$
\begin{gathered}
\% \text { contribuiça do alimento }=\frac{\text { energia do alimento }}{\text { energia to tal do grupo alimentar }} \times 100 \\
\mathrm{e}
\end{gathered}
$$

$$
\% \text { contribuição do alimento }=\frac{\text { gramas do alimento }}{\text { gramas do grupo alimentar }} \times 100
$$

Foram selecionados os alimentos que contribuíram com até $95 \%$ do consumo total em gramas e em porcentagem de energia. ${ }^{31}$

Para a análise dos indivíduos que alcançaram e não alcançaram a recomendação do consumo de $F r, V \& L$, em gramas e em porcentagem da energia total consumida, foram utilizadas as referências da Organização Mundial da Saúde - OMS: consumo mínimo de 400 gramas e de 9,0\% da energia total da dieta, e do "World Cancer Research Fund - WCRF" (Fundo Mundial para a Pesquisa em Câncer): consumo mínimo 400 - 600 gramas de hortaliças (sem amido) e de frutas de diferentes cores. Foi realizada categorização do consumo de Fr,V\&L em gramas: consumo abaixo, igual ou maior do que as recomendações, conforme discriminado no quadro 2. Para análise da adequação em termos de porcentagem de energia da dieta fornecida por Fr,V\&L foram adotadas duas categorias: abaixo da recomendação e igual ou maior do que a recomendação. 
Quadro 2 - Categorização quanto ao consumo de Fr,V\&L em gramas e em porcentagem de energia, segundo as recomendações da OMS e WCRF.

\begin{tabular}{|lcc|}
\hline & Recomendações & Categorias \\
\hline \hline Consumo de Fr, V\&L em gramas & $<400$ & \\
& 400 a 599 & Abaixo \\
& $600 \mathrm{ou}+$ & Igual \\
& & Maior \\
Consumo de Fr, V\&L em \% energia & $<9,0$ & Abaixo \\
& $9,0 \mathrm{e}+$ & Igual/maior \\
\hline
\end{tabular}

Para o conjunto das variáveis quantitativas foi realizada análise descritiva segundo medidas de tendência central e de dispersão (média, mediana, desvio padrão, valor máximo e mínimo). As variáveis qualitativas foram descritas em freqüência absoluta e percentual.

A identificação dos fatores associados ao consumo de $\mathrm{Fr}, \mathrm{V} \& \mathrm{~L}$ foi guiada pelo modelo de análise do consumo de frutas, verduras e legumes em adultos apresentado na Figura 2. Foram comparados os consumos de Fr,V\&L (em gramas, ajustado por energia, e em porcentagem de energia da dieta fornecida por este grupo alimentar) segundo categorias de escolaridade, idade, sexo, IMC, presença de morbidades e participação em atendimento nutricional, utilizando-se o teste de Wilcoxon ou da Mediana, para variáveis com duas categorias e o teste de Kruskal-Wallis, para variáveis com mais de duas categorias. $O$ valor de $p<0,05$ foi adotado como significante. Também foram investigadas correlações entre o consumo de Fr,V\&L com idade e IMC, através do teste t-student.

A análise dos dados foi realizada através do Programa Statistical Analysis System (SAS for Windows, v.9.1.3). 


\subsection{Aspectos éticos}

O presente estudo seguiu as normas estabelecidas pela resolução $n^{0}$ 196 de 10 de outubro de 1996 do Conselho Nacional de Saúde para pesquisa envolvendo seres humanos. Foi encaminhado para a apreciação e parecer do Comitê de Ética Médica da Faculdade de Medicina de Botucatu, obtendo parecer favorável à sua realização - Anexo 3. O consentimento livre e esclarecido - Anexo 4 foi obtido no primeiro contato com os entrevistados, na ocasião foi esclarecido que a pesquisa não apresentaria risco, desconforto e inconveniências. O entrevistado foi esclarecido que teria a liberdade de recusar ou retirar seu consentimento, a qualquer momento, sem nenhuma penalização. Foi fornecida ao entrevistado uma cópia do termo de consentimento. 


\section{Resultadas}

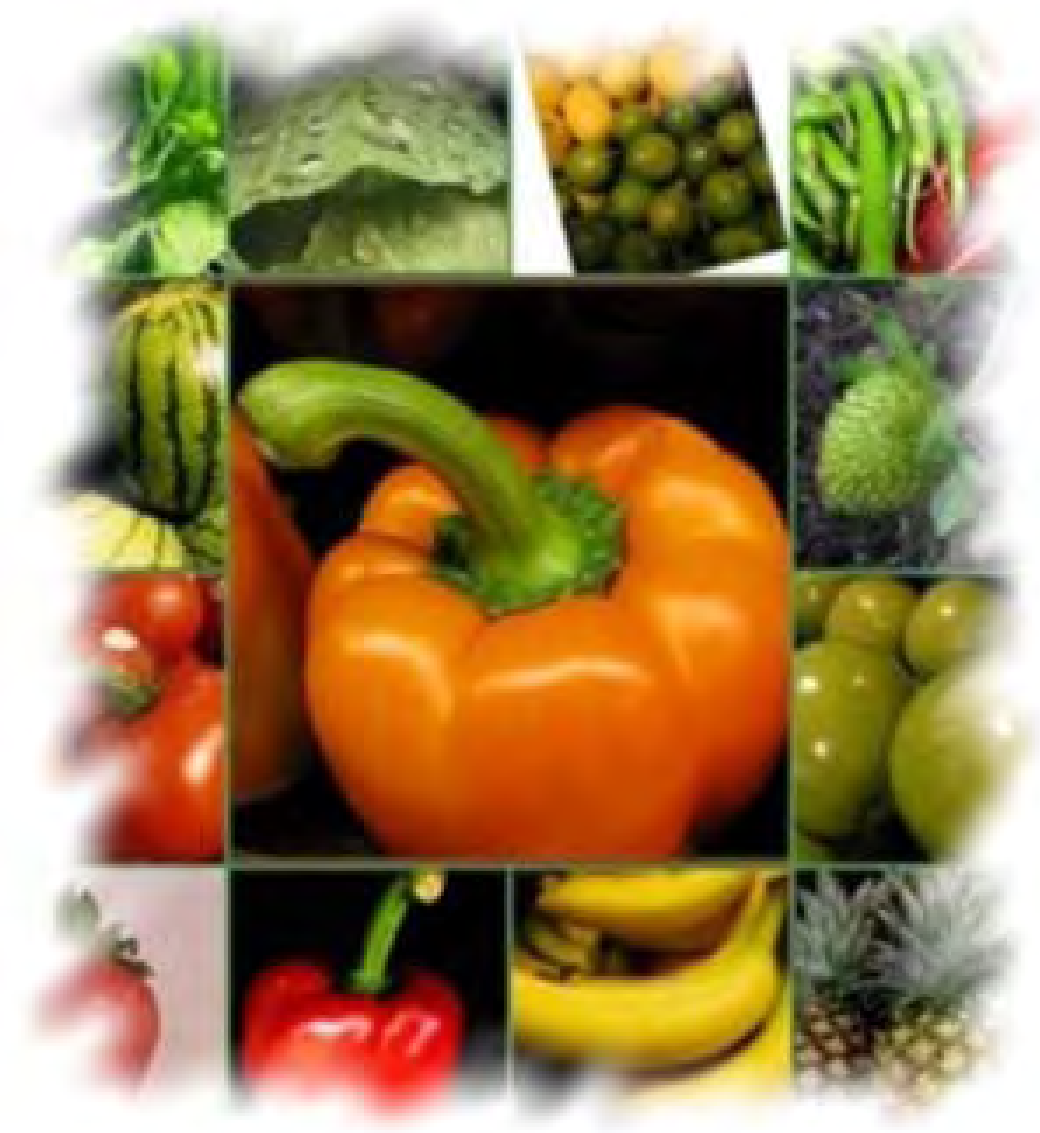




\subsection{Características da população}

A amostra final foi composta por 181 pessoas $(\mathrm{N}=181)$, sendo 125 $(69,06 \%)$ do sexo feminino e $56(30,94 \%)$ do sexo masculino. A idade média foi de 56,42 anos (DP=16,34), com idade mínima de 18 anos e idade máxima de 86 anos. Houve predomínio de indivíduos na faixa etária < 60 anos, 55,80\%. Com relação à escolaridade, houve predomínio na faixa de 4 a 7 anos de estudo, 38,12\%, seguida da faixa de 0 a 3 anos, 30,39\%. Apenas 5,52\% dos adultos estudados tinham 12 ou mais anos de estudo. Com relação ao IMC, $34,25 \%$ encontravam-se eutróficos, $41,99 \%$ em sobrepeso e 23,76\% obesos, ou seja, 65,75\% dos indivíduos encontravam-se com excesso de peso. A morbidade pessoal diagnosticada mais freqüente foi hipertensão - 43,60\%, seguida de dislipidemia - 34,25\%, diabetes - 19,33\%, hipotireoidismo - 6,62\%, doença cardiovascular - 6,07\% e intolerância à glicose - 2,76\% (Tabela 1). Dos indivíduos avaliados $87,85 \%$ apresentavam uma ou mais morbidade diagnosticada e 12,15\% não apresentavam nenhuma morbidade, ou seja, a maioria dos indivíduos apresentavam uma condição crônica de saúde. 
Tabela 1 - Distribuição numérica e percentual da população estudada segundo características demográficas, socioeconômica, nutricional e presença de morbidades específicas ( $\mathrm{N}=181)$.

\begin{tabular}{|c|c|c|}
\hline & $\mathbf{N}$ & Porcentagem (\%) \\
\hline \multicolumn{3}{|l|}{ IDADE } \\
\hline$<60$ anos & 101 & 55,80 \\
\hline$\geq 60$ anos & 80 & 44,20 \\
\hline \multicolumn{3}{|c|}{ ESCOLARIDADE } \\
\hline 0-3 anos & 55 & 30,39 \\
\hline 4-7 anos & 69 & 38,12 \\
\hline 8-11 anos & 47 & 25,97 \\
\hline$\geq 12$ anos & 10 & 5,52 \\
\hline \multicolumn{3}{|l|}{ SEXO } \\
\hline Feminino & 125 & 69,06 \\
\hline Masculino & 56 & 30,94 \\
\hline \multicolumn{3}{|l|}{ IMC } \\
\hline Eutrofia & 62 & 34,25 \\
\hline Sobrepeso & 76 & 41,99 \\
\hline Obesidade & 43 & 23,76 \\
\hline \multicolumn{3}{|c|}{ MORBIDADES } \\
\hline \multicolumn{3}{|l|}{ Diabetes } \\
\hline Sim & 35 & 19,33 \\
\hline Não & 146 & 80,66 \\
\hline \multicolumn{3}{|c|}{ Hipertensão } \\
\hline Sim & 79 & 43,60 \\
\hline Não & 102 & 56,33 \\
\hline \multicolumn{3}{|l|}{ Dcv } \\
\hline Sim & 11 & 6,07 \\
\hline Não & 170 & 93,92 \\
\hline \multicolumn{3}{|c|}{ Dislipidemia } \\
\hline Sim & 62 & 34,25 \\
\hline Não & 119 & 65,74 \\
\hline \multicolumn{3}{|c|}{ Intolerância à glicose } \\
\hline Sim & 05 & 2,76 \\
\hline Não & 176 & 97,23 \\
\hline \multicolumn{3}{|c|}{ Hipotireoidismo } \\
\hline Sim & 12 & 6,62 \\
\hline Não & 169 & 93,37 \\
\hline \multicolumn{3}{|c|}{ Outras morbidades } \\
\hline Sim & 87 & 48,06 \\
\hline Não & 94 & 51,93 \\
\hline
\end{tabular}


$\mathrm{Na}$ tabela 2, apresentam-se os dados da participação dos indivíduos estudados em ações de saúde que envolvem educação e orientação alimentar, conforme as diferentes modalidades de atendimento e abordagem nutricional oferecidas na área de Atenção ao Adulto. Observou-se que 14,36\% dos indivíduos participaram do atendimento nutricional individual e 5,52\% de atividade educativa em grupo; somados, 19,88\% dos indivíduos avaliados participaram de algum tipo das diferentes modalidades de atendimento envolvendo orientação alimentar. As atividades educativas realizadas em sala de espera (AESE) não foram consideradas, pois não há registro em prontuário por tratar-se de uma atividade livre e voltada para os usuários que se encontrarem naquele momento aguardando atendimento.

Tabela 2 - Distribuição numérica e percentual da população estudada segundo a participação dos indivíduos nas diferentes modalidades de atendimento e abordagem nutricional oferecidas na área de Atenção ao Adulto. $(\mathrm{N}=181)$.

\begin{tabular}{lcc}
\hline & N & Porcentagem (\%) \\
Atendimento Nutricional Individual & & \\
Sim & 26 & 14,36 \\
Não & 155 & 85,64 \\
Atividade Educativa Grupo & & \\
Sim & 10 & 5,52 \\
Não & 171 & 94,48 \\
\hline
\end{tabular}


Os valores médios e medianos do consumo diário de Fr,V\&L, em gramas (valor bruto e ajustado por energia consumida), em energia, em porcentagem do total de energia da dieta e a energia total da dieta consumida pelos entrevistados são apresentados na tabela 3. Os valores referentes aos percentis 25 e 75 do consumo de $\mathrm{Fr}, \mathrm{V} \& \mathrm{~L}$, em gramas ajustado por energia, e em porcentagem da energia da dieta, são também apresentados. A mediana do consumo de Fr,V\&L, ajustada por energia, foi de 216,63 gramas, mínimo de 0,0 e máximo de 1454,23 gramas, sendo o consumo médio igual a 281,36 gramas $(\mathrm{DP}=274,70)$. A porcentagem mediana de energia da dieta fornecida por este grupo alimentar foi igual a 7,48\% e a média igual a 8,72\%. Observouse ampla variação do percentual de energia da dieta aportado por Fr,V\&L: menor contribuição igual a 0,00\% e maior igual a 41,13\%.

Tabela 3 - Valores médios, medianos e percentis do consumo diário de Fr,V\&L bruto e ajustado, em gramas (g), energia (Cal), porcentagem (\%) de energia da dieta e a energia ( $\mathrm{Cal})$ total da dieta consumida pelos entrevistados $(\mathrm{N}=181)$.

\begin{tabular}{ccrrrrrrrr}
\hline & N & Mediana & Média & DP & Mínimo & Máximo & P25 & P75 \\
\hline $\begin{array}{c}\text { Fr,V\&L (g) } \\
\text { Bruto }\end{array}$ & 181 & 203,00 & 293,46 & 293,15 & 0,00 & 1530,00 & - & - \\
\hline $\begin{array}{c}\text { Fr,V\&L (g) } \\
\text { Ajustado }\end{array}$ & 181 & 216,63 & 281,36 & 274,70 & 0,00 & 1454,23 & 77,75 & 406,16 \\
$\begin{array}{c}\text { Fr,V\&L } \\
\text { Energia }\end{array}$ & 181 & 95,70 & 131,85 & 145,52 & 0,00 & 841,76 & - & - \\
$\begin{array}{c}\text { \% energia } \\
\text { da dieta }\end{array}$ & 181 & 7,48 & 8,72 & 8,07 & 0,00 & 41,13 & 1,27 & 13,30 \\
$\begin{array}{c}\text { Energia } \\
\text { Total da } \\
\text { dieta }\end{array}$ & 181 & 1433,00 & 1529,55 & 671,30 & 533,66 & 4248,02 & - & - \\
\hline
\end{tabular}


Estatísticas descritivas detalhadas do consumo de Fr,V\&L (em gramas, ajustado por energia e em porcentagem da energia da dieta) são apresentadas nas Figuras 3 e 4 (Box-plots). Pode-se observar a grande concentração de indivíduos nos valores inferiores e também a presença de alguns indivíduos com consumo muito alto, sendo ampla a variação entre consumo mínimo e máximo.

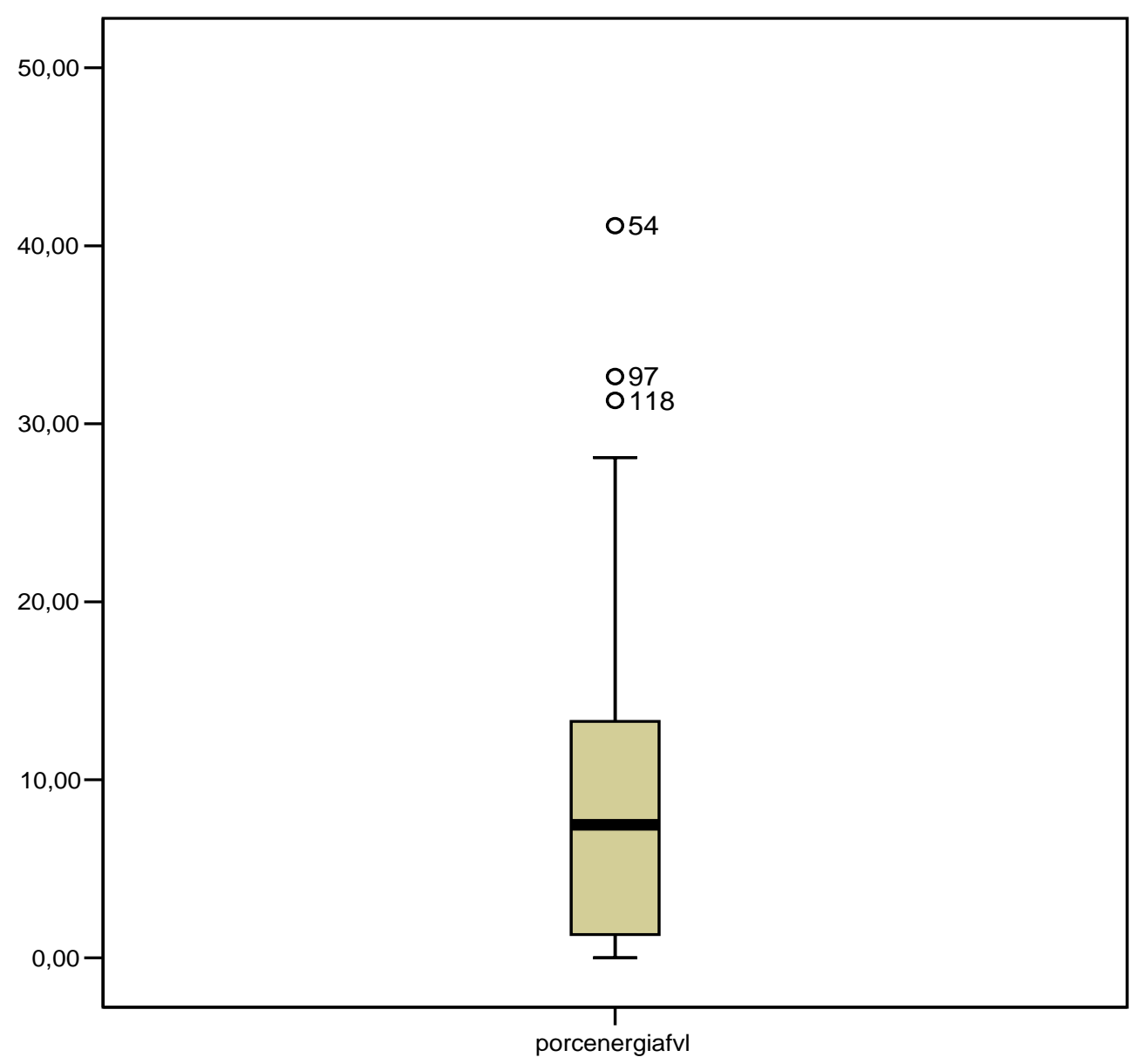

Figura 3 - Box-plot referente à variável consumo de Fr,V\&L em porcentagem da energia da dieta. 


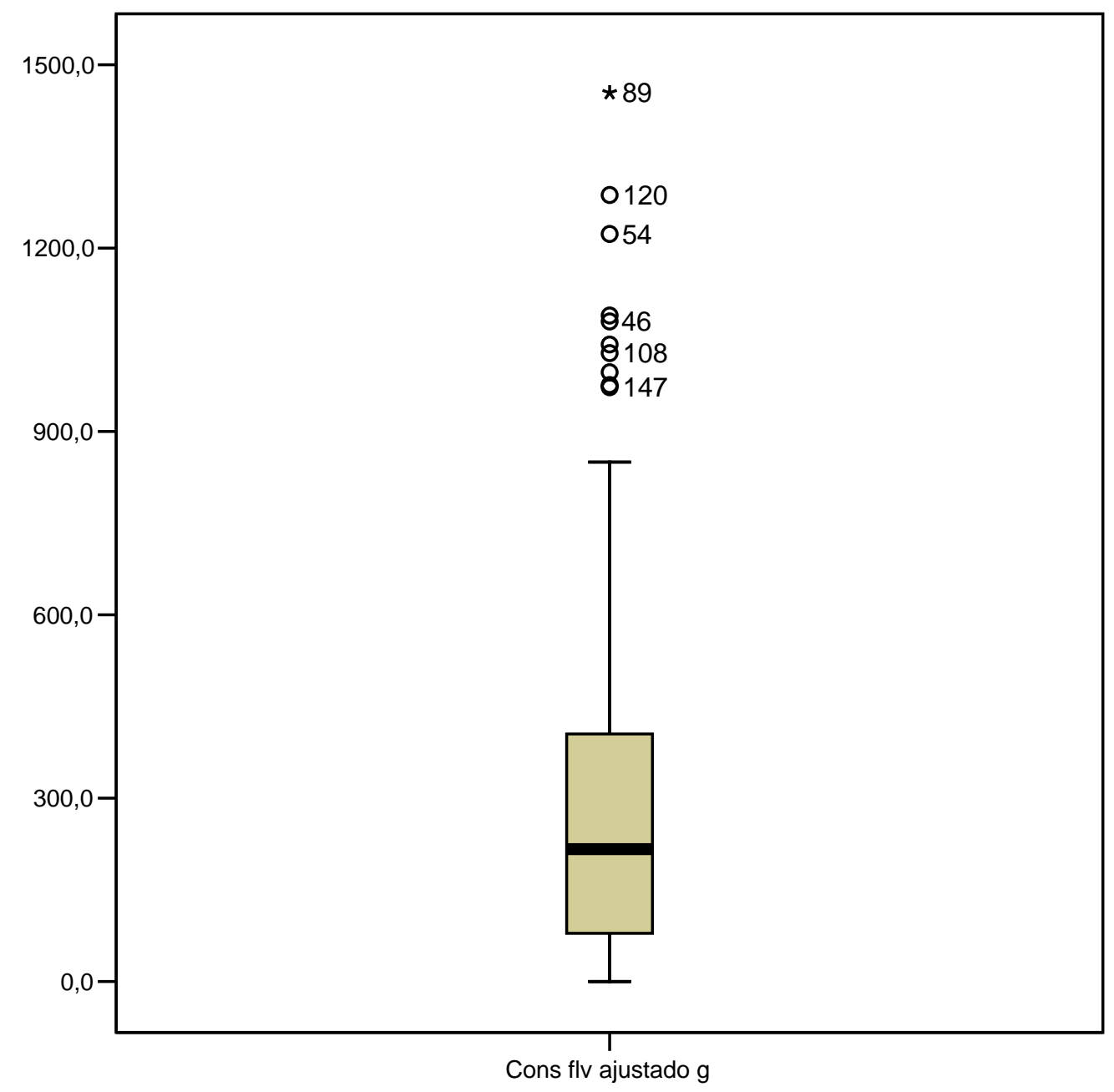

Figura 4 - Box-plot referente à variável consumo de Fr,V\&L em gramas. 
Na tabela 4 são apresentadas as distribuições dos indivíduos estudados segundo categoria de consumo de Fr,V\&L: consumo baixo, adequado ou acima das recomendações, para valores em gramas; consumo baixo e consumo adequado, para valores em porcentagem de energia da dieta. Podese observar que $73,5 \%$ consumiram abaixo de $400 \mathrm{~g}$, valor mínimo recomendado pela OMS e 91,7\% abaixo de 600g, valor recomendado pelo WCRF. Se considerarmos a recomendação de consumo mínimo igual a 9\% da energia total da dieta, os resultados são mais favoráveis, porém ainda 59,1\% não alcançaram este parâmetro. Cabe ainda apontar que 16 (8,8\%) indivíduos não consumiram Fr,V\&L e que 20,4\% apresentaram consumo abaixo de 1,0\% da energia da dieta.

Tabela 4 - Distribuição dos indivíduos estudados segundo categoria de consumo de Fr,V\&L em gramas e porcentagem da energia da dieta, conforme as recomendações da OMS e WCRF (N=181).

\begin{tabular}{lrc}
\hline & N & Porcentagem (\%) \\
Consumo de Fr,V\&L em gramas & 133 & \\
$<400$ & 33 & 18,5 \\
400 a 599 & 15 & 8,3 \\
600 ou + & & \\
Consumo de Fr, V\&L em \% energia & 107 & 59,1 \\
$<9,0$ & 74 & 40,9 \\
9,0 e + & & \\
\hline
\end{tabular}

$\mathrm{Na}$ tabela 5, apresenta-se a lista das frutas, verduras e legumes consumidas em ordem decrescente de freqüência de consumidores. Foram consumidos 49 itens deste grupo alimentar, sendo o alimento consumido por maior número de pessoas a alface (74, 40,88\%), seguido da laranja/mexerica $(58,32,04 \%)$, banana $(52,28,72 \%)$ e do tomate $(50,27,62 \%)$, mamão (22, $12,15 \%)$, cenoura $(21,11,60 \%)$, maçã $(19,10,49 \%)$, pepino $(15,8,28 \%)$, rúcula $(12,6,62 \%)$, limão $(10,5,52 \%)$, repolho $(10,5,52 \%)$ e abobrinha $(10,5,52 \%)$. Pode-se observar que $8,83 \%$ dos indivíduos, não consumiram nenhum alimento deste grupo alimentar. 
Tabela 5 - Distribuição numérica e porcentagem em ordem decrescente de indivíduos segundo os alimentos consumidos do grupo de Fr, V\&L (N=181).

\begin{tabular}{|c|c|c|}
\hline \multirow[t]{2}{*}{ ALIMENTO } & \multicolumn{2}{|c|}{ No CONSUMIDORES } \\
\hline & $\mathbf{N}$ & Porcentagem \\
\hline Alface & 74 & 40,88 \\
\hline Laranja/mexerica & 58 & 32,04 \\
\hline Banana & 52 & 28,72 \\
\hline Tomate & 50 & 27,62 \\
\hline Mamão & 22 & 12,15 \\
\hline Cenoura & 21 & 11,60 \\
\hline Maçã & 19 & 10,49 \\
\hline Pepino & 15 & 8,28 \\
\hline Rúcula & 12 & 6,62 \\
\hline Limão & 10 & 5,52 \\
\hline Repolho & 10 & 5,52 \\
\hline Abobrinha & 10 & 5,52 \\
\hline Caqui & 9 & 4,97 \\
\hline Chicória & 9 & 4,97 \\
\hline Berinjela & 9 & 4,97 \\
\hline Suco, laranja/mexerica* & 8 & 4,41 \\
\hline Pêra & 7 & 3,86 \\
\hline Melancia & 6 & 3,31 \\
\hline Cebola & 6 & 3,31 \\
\hline Abacate & 5 & 2,76 \\
\hline Suco, maracujá* & 5 & 2,76 \\
\hline Couve & 5 & 2,76 \\
\hline Agrião & 5 & 2,76 \\
\hline Almeirão & 5 & 2,76 \\
\hline Alho & 5 & 2,76 \\
\hline Suco, abacaxi/hortelã & 4 & 2,20 \\
\hline Chuchu & 4 & 2,20 \\
\hline Pimentão & 4 & 2,20 \\
\hline Uva Itália & 3 & 1,65 \\
\hline
\end{tabular}


Tabela 5 - Distribuição numérica e porcentagem em ordem decrescente de indivíduos segundo os alimentos consumidos do grupo de Fr,V\&L (N=181). Continuação.

\begin{tabular}{llc}
\hline ALIMENTO & N & $\mathbf{N}^{\circ}$ CONSUMIDORES \\
\hline Suco, acerola & 3 & Porcentagem \\
\hline Abóbora & 3 & 1,65 \\
\hline Fruta do Conde & 2 & 1,65 \\
\hline Suco, melancia* & 2 & 1,10 \\
\hline Couve-flor & 2 & 1,10 \\
\hline Brócolis & 2 & 1,10 \\
\hline Acelga & 2 & 1,10 \\
\hline Quiabo & 1 & 1,10 \\
\hline Ameixa & 1 & 0,55 \\
\hline Abacaxi & 1 & 0,55 \\
\hline Melão & 1 & 0,55 \\
\hline Maracujá & 1 & 0,55 \\
\hline Beterraba & 1 & 0,55 \\
\hline Abiu & 1 & 0,55 \\
\hline Carambola & 1 & 0,55 \\
\hline Manga & 1 & 0,55 \\
\hline Espinafre & 1 & 0,55 \\
\hline Salsinha & 1 & 0,55 \\
\hline Cebolinha & 1 & 0,55 \\
\hline Salsão & 1 & 0,55 \\
\hline & & 0,55 \\
\hline
\end{tabular}


A lista das frutas consumidas pela população estudada está na tabela 6 . Pode-se verificar que laranja/mexerica foi a fruta consumida por maior número de indivíduos $(58,32,04 \%)$, seguida da banana $(52,28,72 \%)$, mamão (22, $12,15 \%)$, maçã $(19,10,49 \%)$ e limão $(10,5,52 \%)$. As demais foram consumidas por menos de $5 \%$ dos indivíduos. Os sucos naturais mais consumidos foram de laranja/mexerica $(08,4,41 \%)$ e maracujá $(05,2,76 \%)$. Pode-se observar que 30,94\% (N=56) dos indivíduos, não consumiram nenhuma fruta e 69,06\% (N=125) consumiram ao menos uma fruta no dia.

Tabela 6 - Distribuição numérica e porcentagem em ordem decrescente de indivíduos segundo os alimentos consumidos do grupo das Frutas ( $\mathrm{N}=181)$.

\begin{tabular}{lcc}
\hline ALIMENTO & N & $N^{\circ}$ CONSUMIDORES \\
\hline Laranja/mexerica & 58 & Porcentagem \\
\hline Banana & 52 & 28,04 \\
\hline Mamão & 22 & 12,15 \\
\hline Maçã & 19 & 10,49 \\
\hline Limão & 10 & 5,52 \\
\hline Caqui & 9 & 4,97 \\
\hline Suco, laranja/mexerica * & 8 & 4,41 \\
\hline Pêra & 7 & 3,86 \\
\hline Melancia & 6 & 3,31 \\
\hline Abacate & 5 & 2,76 \\
\hline Suco, maracujá * & 5 & 2,76 \\
\hline Suco, abacaxi com Hortelã * & 4 & 2,20 \\
\hline Uva Itália & 3 & 1,65 \\
\hline Suco, acerola * & 3 & 1,65 \\
\hline Fruta do Conde & 2 & 1,10 \\
\hline Suco, melancia * & 2 & 1,10 \\
\hline Ameixa & 1 & 0,55 \\
\hline Abacaxi & 1 & 0,55 \\
\hline Melão & 1 & 0,55 \\
\hline Maracujá & 1 & 0,55 \\
\hline Abiu & 1 & 0,55 \\
\hline Carambola & 1 & 0,55 \\
\hline Manga & 1 & 0,55 \\
\hline * sucos naturais, sem aćcar & 1 & \\
\hline
\end{tabular}

* sucos naturais, sem açúcar 
$\mathrm{Na}$ tabela 7, apresenta-se a lista das verduras consumidas pela população estudada. Pode-se verificar que a mais freqüente foi a alface (74, $40,88 \%)$, seguida de rúcula $(12,6,62 \%)$ e repolho $(10,5,52 \%)$. Todas as demais foram consumidas por menos de $5 \%$ dos indivíduos. Pode-se também observar que 38,12\% ( $\mathrm{N}=69)$ dos indivíduos não consumiram nenhuma verdura e $61,88 \%(N=112)$ consumiram pelo menos uma verdura no dia.

Tabela 7- Distribuição numérica e porcentagem em ordem decrescente de indivíduos segundo os alimentos consumidos do grupo das Verduras ( $\mathrm{N}=181)$.

\begin{tabular}{lcc}
\hline \multicolumn{1}{c}{ ALIMENTO } & & $\mathbf{N}^{\circ}$ CONSUMIDORES \\
\hline Alface & N & Porcentagem \\
\hline Rúcula & 14 & 40,88 \\
\hline Repolho & 12 & 6,62 \\
\hline Chicória & 10 & 5,52 \\
\hline Couve & 9 & 4,97 \\
\hline Agrião & 5 & 2,76 \\
\hline Almeirão & 5 & 2,76 \\
\hline Couve-flor & 5 & 2,76 \\
\hline Brócolis & 2 & 1,10 \\
\hline Acelga & 2 & 1,10 \\
\hline Espinafre & 2 & 1,10 \\
\hline Salsinha & 1 & 0,55 \\
\hline Cebolinha & 1 & 0,55 \\
\hline Salsão & 1 & 0,55 \\
\hline
\end{tabular}


$\mathrm{Na}$ tabela 8, apresenta-se a lista dos legumes consumidos pela população estudada. Pode-se verificar que o mais freqüente foi o tomate (50, $27,62 \%)$, seguido da cenoura $(21,11,60 \%)$, pepino $(15,8,28 \%)$ e abobrinha $(10,5,52 \%)$. Os demais legumes foram consumidos por menos de $5 \%$ dos indivíduos e pode-se observar que 50,83\% (N=92) dos indivíduos não consumiram nenhum legume e 49,17\% ( $N=89)$ consumiram pelo menos um legume no dia.

Tabela 8 - Distribuição numérica e porcentagem em ordem decrescente de indivíduos segundo os alimentos consumidos do grupo dos Legumes ( $N=181)$.

\begin{tabular}{lcc}
\hline \multicolumn{1}{c}{ ALIMENTO } & & $\mathbf{N}^{\circ}$ CONSUMIDORES \\
\hline Tomate & N & Porcentagem \\
\hline Cenoura & 50 & 27,62 \\
\hline Pepino & 21 & 11,60 \\
\hline Abobrinha & 15 & 8,28 \\
Berinjela & 10 & 5,52 \\
\hline Cebola & 9 & 4,97 \\
Alho & 6 & 3,31 \\
\hline Chuchu & 5 & 2,76 \\
Pimentão & 4 & 2,20 \\
\hline Abóbora & 4 & 2,20 \\
\hline
\end{tabular}


$\mathrm{Na}$ tabela 9, apresentam-se os alimentos consumidos pelos entrevistados segundo sua contribuição percentual para o total de Fr,V\&L consumido pelo conjunto da população estudada, em porcentagem de energia e em gramas. Foram apresentados os alimentos que contribuíram com até 95\% do total consumido, em ordem decrescente de sua contribuição. Pode-se verificar que as frutas contribuíram mais em termos de energia do que as verduras e legumes. A laranja/mexerica foi o alimento quem mais contribuiu, com $26,89 \%$, seguida da banana $18,11 \%$, maçã $7,68 \%$, abacate $7,46 \%$, mamão $5,11 \%$ e suco de laranja $3,83 \%$. Os legumes e as verduras contribuíram com menor porcentagem do total de energia. A alface, o terceiro alimento que mais contribuiu para o total de Fr,V\&L consumido pelos indivíduos, em gramas, e foi o primeiro em freqüência de consumidores, contribuiu com apenas $2,07 \%$ do total energético.

Tabela 9 - Alimentos consumidos em ordem decrescente de sua contribuição para o consumo total de Fr,V\&L, em porcentagem (\%) da energia e em gramas.

\begin{tabular}{lrlr}
\hline \multicolumn{1}{c}{ Alimento } & $\begin{array}{c}\text { Contribuição } \\
\text { \% energia }\end{array}$ & \multicolumn{1}{c}{ Alimento } & $\begin{array}{r}\text { Contribuição } \\
\text { gramas }\end{array}$ \\
\hline Laranja/mexerica & 26,89 & Laranja/mexerica & 28,31 \\
\hline Banana & 18,11 & Banana & 8,70 \\
\hline Maçã & 7,68 & Alface & 7,38 \\
\hline Abacate & 7,46 & Mamão & 6,77 \\
\hline Mamão & 5,11 & Maçã & 5,94 \\
\hline Melancia & 3,99 & Tomate & 5,74 \\
\hline Caqui & 3,43 & Melancia & 5,60 \\
\hline Suco, laranja/mexerica* & 3,83 & Suco, laranja/mexerica* & 3,84 \\
\hline Tomate & 2,68 & Suco, abacaxi/hortelã * & 2,81 \\
\hline Pêra & 2,11 & Pepino & 2,57 \\
\hline Alface & 2,07 & Caqui & 2,20 \\
\hline Chicória & 1,56 & Abacate & 2,08 \\
\hline Suco, abacaxi/hortelã * & 1,38 & Pêra & 1,60 \\
\hline Ameixa & 1,36 & Suco, melancia* & 1,17 \\
\hline
\end{tabular}


Tabela 9 - Alimentos consumidos em ordem decrescente de sua contribuição para o consumo total de $\mathrm{Fr}, \mathrm{V} \& \mathrm{~L}$, em porcentagem (\%) da energia e em gramas. Continuação.

\begin{tabular}{lclc}
\hline \multicolumn{1}{c}{ Alimento } & $\begin{array}{c}\text { Contribuição } \\
\text { \% energia }\end{array}$ & \multicolumn{1}{c}{ Alimento } & $\begin{array}{r}\text { Contribuição } \\
\text { gramas }\end{array}$ \\
\hline Cenoura & 1,08 & Ameixa & 1,11 \\
\hline Fruta do Conde & 1,00 & Cenoura & 1,10 \\
\hline Suco, maracujá * & 0,95 & Abobrinha & 1,10 \\
\hline Uva Itália & 0,90 & Suco, acerola* & 1,08 \\
\hline Abacaxi & 0,82 & Limão & 1,03 \\
\hline Pepino & 0,74 & Melão & 0,94 \\
Suco, melancia* & 0,73 & Chicória & 0,89 \\
\hline Melão & 0,73 & Repolho & 0,83 \\
& & Rúcula & 0,81 \\
\hline
\end{tabular}

* sucos naturais, sem açúcar

A tabela 10 apresenta a quantidade total, em gramas e em porcentagem de energia, de frutas consumidas pelos entrevistados. Foram listados os alimentos que contribuíram com até 95\% do consumo total, em porcentagem de energia e em gramas. Pode-se verificar que a laranja/mexerica foi 0 alimento do grupo que contribuiu com a maior porcentagem da energia 30,44\%, seguido pela banana 20,49\%, maçã $8,69 \%$, abacate $8,44 \%$, mamão $5,78 \%$, melancia 4,52\%, suco de laranja/mexerica $4,33 \%$, caqui $3,89 \%$. O suco de maracujá contribuiu menos em termos energéticos. 
Tabela 10 - Frutas consumidas em ordem decrescente de sua contribuição para o consumo deste grupo, em porcentagem (\%) da energia e em gramas (g).

\begin{tabular}{lrlc}
\hline \multicolumn{1}{c}{ Alimento } & $\begin{array}{c}\text { Contribuição } \\
\text { \% energia }\end{array}$ & \multicolumn{1}{c}{ Alimento } & $\begin{array}{c}\text { Contribuição } \\
\text { gramas }\end{array}$ \\
\hline Laranja/mexerica & 30,44 & Laranja/mexerica & 37,16 \\
\hline Banana & 20,49 & Banana & 11,41 \\
\hline Maçã & 8,69 & Mamão & 8,88 \\
\hline Abacate & 8,44 & Maçã & 7,79 \\
\hline Mamão & 5,78 & Melancia & 7,36 \\
\hline Melancia & 4,52 & Suco, abacaxi /hortelã & 3,69 \\
\hline Suco, laranja/mexerica* & 4,33 & Suco, laranja/mexerica* & 5,04 \\
\hline Caqui & 3,89 & Caqui & 2,89 \\
\hline Pêra & 2,38 & Abacate & 2,73 \\
\hline Suco, abacaxi/hortelã * & 1,56 & Pêra & 2,10 \\
\hline Ameixa & 1,54 & Suco, melancia* & 1,54 \\
\hline Fruta do Conde & 1,13 & Ameixa & 1,46 \\
\hline Suco, maracujá * & 1,08 & Suco, acerola* & 1,41 \\
\hline
\end{tabular}

* sucos naturais, sem açúcar 
Da mesma forma, na tabela 11, apresenta-se a quantidade total, em gramas e em porcentagem de energia, de verduras consumidas pelos entrevistados. Também foram selecionados os alimentos que contribuíram com até 95\% do consumo total em porcentagem de energia e em gramas. Pode-se verificar que a alface contribuiu com a maior porcentagem de energia 37,02\%, seguida da chicória 27,99\%, couve $11,74 \%$, repolho $7,56 \%$ e rúcula $5,56 \%$. Todos os demais alimentos contribuíram com menos de $5 \%$ do total energético fornecido por este grupo de alimentos.

Tabela 11 - Verduras consumidas em ordem decrescente de sua contribuição para o consumo deste grupo, em porcentagem (\%) da energia e em gramas (g).

\begin{tabular}{cccc}
\hline Alimento & $\begin{array}{c}\text { Contribuição \% } \\
\text { energia }\end{array}$ & Alimento & $\begin{array}{c}\text { Contribuição } \\
\text { gramas }\end{array}$ \\
\hline Alface & 37,02 & Alface & 63,37 \\
Chicória & 27,99 & Chicória & 7,55 \\
Couve & 11,74 & Repolho & 7,06 \\
\hline Repolho & 7,56 & Rúcula & 6,87 \\
Rúcula & 5,56 & Agrião & 5,79 \\
\hline Agrião & 2,99 & Couve & 2,86 \\
\hline
\end{tabular}

Finalmente, na tabela 12, apresenta-se a quantidade total, em gramas e em porcentagem de energia, de legumes consumidos pelos entrevistados. Também foram selecionados os alimentos que contribuíram com até $95 \%$ do consumo total. Pode-se verificar que o tomate contribuiu com a maior porcentagem da energia 44,28\%, seguido pela cenoura $17,81 \%$, pepino $12,28 \%$, abobrinha $6,47 \%$, berinjela $5,64 \%$, chuchu $3,45 \%$, beterraba $2,42 \%$ e cebola $2,17 \%$. 
Tabela 12 - Legumes consumidos em ordem decrescente de sua contribuição para o consumo deste grupo, em porcentagem (\%) da energia e em gramas (g).

\begin{tabular}{cclc}
\hline Alimento & $\begin{array}{c}\text { Contribuição \% } \\
\text { energia }\end{array}$ & Alimento & $\begin{array}{c}\text { Contribuição } \\
\text { gramas }\end{array}$ \\
\hline Tomate & 44,28 & Tomate & 46,98 \\
Cenoura & 17,81 & Pepino & 21,05 \\
\hline Pepino & 12,28 & Cenoura & 9,02 \\
\hline Abobrinha & 6,47 & Abobrinha & 9,00 \\
\hline Berinjela & 5,64 & Berinjela & 4,51 \\
\hline Chuchu & 3,45 & Chuchu & 3,21 \\
\hline Beterraba & 2,42 & & \\
\hline Cebola & 2,17 & & \\
\hline
\end{tabular}

$\mathrm{Na}$ tabela 13, apresentam-se as diferenças de consumo de Fr,V\&L segundo idade, sexo, escolaridade, índice de massa corpórea (IMC) e morbidades pessoais diagnosticadas. Houve diferença estatisticamente significativa na mediana do consumo de Fr,V\&L (em porcentagem de energia) segundo sexo, sendo o consumo maior nas mulheres, $(p=0,0106)$. A mediana do consumo de Fr,V\&L, em gramas, ajustado por energia, foi maior na faixa etária $\geq 60$ anos. Com relação à escolaridade, o consumo de Fr,V\&L, em gramas, ajustado, e em porcentagem de energia, foi maior nos idosos com 4 a 7 anos e com mais de 12 anos de estudo. Além disso, o consumo de Fr,V\&L, em gramas, ajustado, e em porcentagem de energia, foi maior nos indivíduos com sobrepeso. Pôde-se também observar maior consumo de Fr,V\&L, em gramas, ajustado e em porcentagem de energia, nos indivíduos com hipertensão, diabetes, DCV e hipotireoidismo. Para os indivíduos com dislipidemia e intolerância à glicose, o resultado foi inverso, ou seja, o consumo de $\mathrm{Fr}, \mathrm{V} \& \mathrm{~L}$, em gramas, ajustado, e em porcentagem de energia foi menor nos portadores do que nos demais. 
Tabela 13 - Comparação entre o consumo de Fr,V\&L em gramas ajustado e em porcentagem de energia entre os fatores selecionados.

\begin{tabular}{|c|c|c|c|c|}
\hline & \multicolumn{2}{|c|}{$\begin{array}{l}\text { Consumo Fr,V\&L em } \\
\text { gramas ajustado }\end{array}$} & \multicolumn{2}{|c|}{$\begin{array}{c}\text { Consumo Fr,V\&L em \% } \\
\text { energia }\end{array}$} \\
\hline & Mediana & $\mathbf{P}$ & Mediana & $\mathbf{P}$ \\
\hline \multicolumn{5}{|l|}{ IDADE } \\
\hline$<60$ anos & 206,92 & 0,1816 & 6,31 & 0,0851 \\
\hline$\geq 60$ anos & 231,97 & & 8,60 & \\
\hline \multicolumn{5}{|c|}{ ESCOLARIDADE } \\
\hline $0-3$ anos & 174,51 & 0,2161 & 3,85 & 0,0742 \\
\hline 4-7 anos & 246,50 & & 8,14 & \\
\hline 8-11 anos & 206,92 & & 6,31 & \\
\hline$\geq 12$ anos & 363,14 & & 13,85 & \\
\hline \multicolumn{5}{|l|}{ SEXO } \\
\hline Feminino & 232,90 & 0,1047 & 8,36 & $0,0106 *$ \\
\hline Masculino & 157,37 & & 2,93 & \\
\hline \multicolumn{5}{|l|}{ IMC } \\
\hline Eutrofia & 187,99 & 0,1913 & 6,10 & $0,0412^{* *}$ \\
\hline Sobrepeso & 239,93 & & 10,76 & \\
\hline Obesidade & 206,92 & & 6,51 & \\
\hline \multicolumn{5}{|c|}{ MORBIDADES } \\
\hline \multicolumn{5}{|l|}{ Diabetes } \\
\hline Sim & 229,54 & 0,2280 & 9,52 & 0,4430 \\
\hline Não & 212,97 & & 6,78 & \\
\hline \multicolumn{5}{|c|}{ Hipertensão } \\
\hline Sim & 229,54 & 0,0732 & 8,36 & 0,1169 \\
\hline Não & 204,15 & & 6,26 & \\
\hline \multicolumn{5}{|l|}{ Dcv } \\
\hline Sim & 231,04 & 0,4668 & 9,24 & 0,9361 \\
\hline Não & 214,27 & & 7,43 & \\
\hline \multicolumn{5}{|c|}{ Dislipidemia } \\
\hline Sim & 175,90 & 0,2091 & 6,21 & 0,8132 \\
\hline Não & 242,08 & & 8,04 & \\
\hline \multicolumn{5}{|c|}{ Intolerância à glicose } \\
\hline Sim & 173,11 & 0,8185 & 6,31 & 0,8864 \\
\hline Não & 217,02 & & 7,53 & \\
\hline \multicolumn{5}{|c|}{ Hipotireoidismo } \\
\hline Sim & 270,18 & 0,5801 & 9,41 & 0,5119 \\
\hline Não & 211,90 & & 7,29 & \\
\hline \multicolumn{5}{|c|}{ Outras morbidades } \\
\hline Sim & 231,04 & 0,3910 & 7,96 & 0,2093 \\
\hline Não & 210,97 & & 7,01 & \\
\hline
\end{tabular}

* Teste Wilcoxon, ** Teste Kruskal-Wallis 
$\mathrm{Na}$ tabela 14, apresentam-se os resultados da investigação das diferenças de consumo de Fr,V\&L segundo o uso do serviço de saúde indicados pela participação em atendimento nutricional individual (ANI) ou atividade educativa em grupo (AEG) no último ano. A mediana do consumo de Fr,V\&L, em gramas ajustado por energia e em porcentagem de energia foi maior nos indivíduos que participaram do ANI em comparação àqueles que não participaram dessa abordagem nutricional, apresentando diferenças estatisticamente significativas em ambos os casos (em gramas e em porcentagem da energia).

Tabela 14 - Comparação entre o consumo de Fr,V\&L em gramas ajustado e em porcentagem de energia segundo o uso do serviço de saúde: atendimento nutricional individual (ANI) e atividade educativa em grupo (AEG) no último ano.

\begin{tabular}{ccccc}
\hline & \multicolumn{2}{c}{ Consumo Fr,V\&L, em } & gramas & \multicolumn{2}{c}{ Consumo Fr,V\&L, em \% energia } \\
\hline & Mediana & P & Mediana & P \\
ANI & & & & \\
Sim & 357,35 & $\mathbf{0 , 0 2 0 6 ^ { * }}$ & 10,66 & $\mathbf{0 , 0 1 5}^{*}$ \\
Não & 206,92 & & 6,61 & \\
AEG & & & & $0,5044^{*}$ \\
Sim & 210,50 & $0,6933^{*}$ & 9,55 & \\
Não & 216,63 & & 7,38 & \\
\hline
\end{tabular}

* Teste Wilcoxon 
Os resultados da investigação de eventuais correlações entre 0 consumo de $\mathrm{Fr}, \mathrm{V} \& \mathrm{~L}$ em gramas ajustado por energia e em porcentagem da energia total com idade e IMC, apresentam-se expressos na tabela 15. Observou-se que o consumo de $\mathrm{Fr}, \mathrm{V} \& \mathrm{~L}$ em gramas, ajustado por energia, não se correlacionou com idade e IMC. Houve correlação entre o consumo de Fr,V\&L em porcentagem de energia e idade, podendo-se dizer que o consumo relativo de Fr,V\&L cresce com o aumento da idade. Quando analisado em termos de porcentagem de energia da dieta, o consumo de $\mathrm{Fr}, \mathrm{V} \& \mathrm{~L}$ não se correlacionou com o IMC dos indivíduos.

Tabela 15 - Coeficiente de correlação e p-valor para as variáveis consumo de Fr,V\&L em gramas ajustado e em porcentagem da energia total com idade e IMC.

\begin{tabular}{ccc}
\hline & Idade & IMC \\
\hline Idade & 1 & \\
IMC & 0,06593 & 1 \\
& $p=0,3779$ & 0,14121 \\
CA & 0,12872 & $p=0,0579$ \\
& $p=0,0842$ & 0,13866 \\
PE & 0,15970 & $p=0,0627$ \\
\hline & $p=0,0318$ & \\
IMC - Índice de massa corpórea, CA - consumo de Fr,V\&L em gramas ajustado, \\
$\mathrm{PE}-$ consumo de Fr,V\&L em porcentagem da energia total.
\end{tabular}




\section{Discussãa}

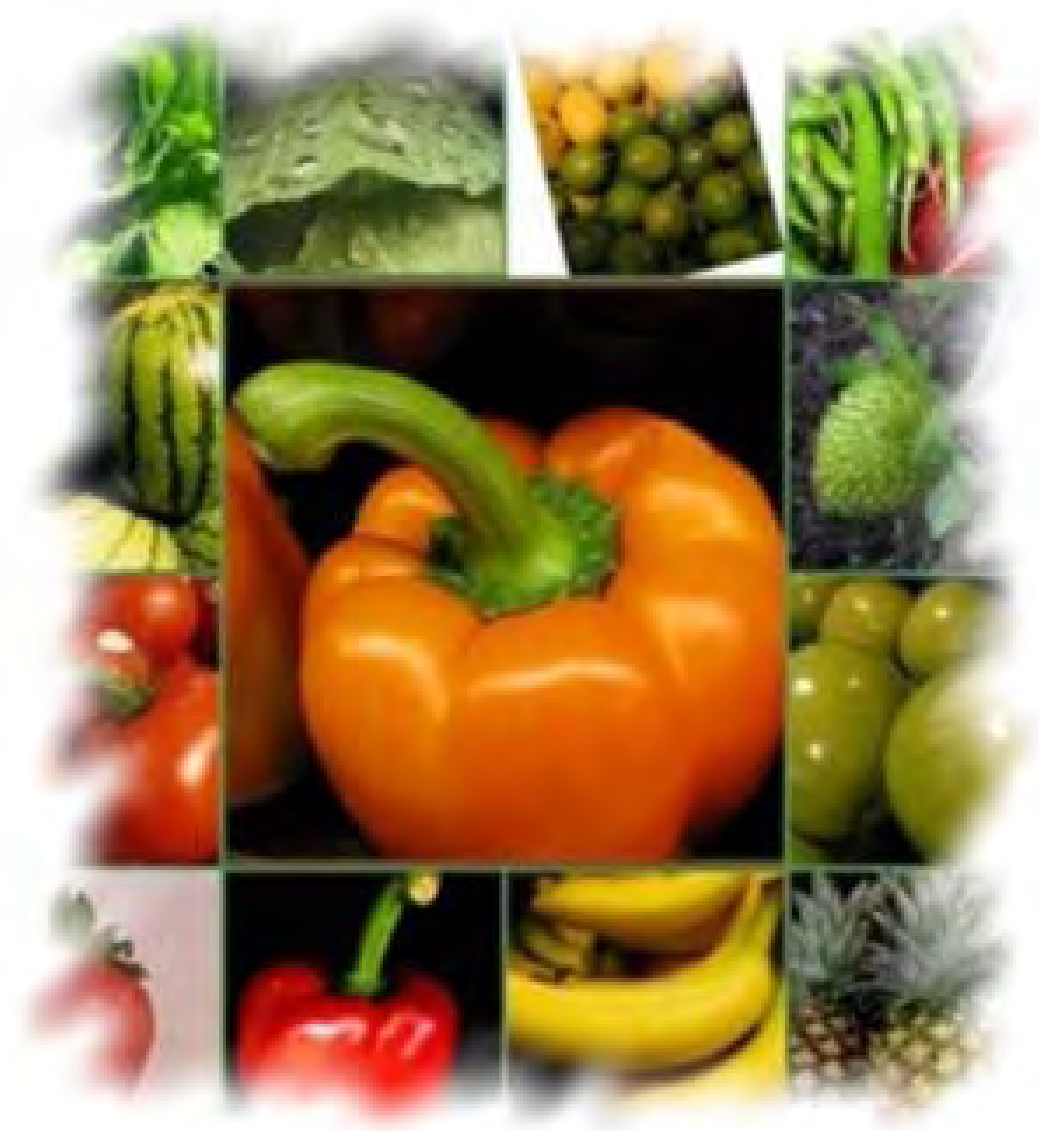


O presente estudo analisou o consumo de Fr,V\&L na população adulta usuária de uma Unidade Básica de Saúde do Sistema Único de Saúde (SUS), formada predominantemente por mulheres, de meia idade e baixa escolaridade, com excesso de peso corporal e alta prevalência de doenças crônicas, sendo as mais freqüentes a hipertensão, seguida de dislipidemia e diabetes.

As Fr,V\&L mais consumidas pela população estudada foram as mais populares, de custo mais baixo e acesso favorecido pela elevada oferta e disponibilidade na região, quais sejam: alface, laranja/mexerica, banana, tomate, mamão, cenoura e maçã.

As características do perfil de consumo encontrado foram avaliadas a partir dos parâmetros definidos pelas recomendações nacionais e internacionais, e serão discutidas em diálogo com a literatura sobre o tema.

O Guia Alimentar para a População Brasileira (Brasil, 2005), recomenda o consumo diário de 3 porções ou mais de frutas (valor calórico médio da porção $=70 \mathrm{Kcal}$ e tamanho médio $=130 \mathrm{~g}$ ) e 3 porções de legumes e verduras (valor calórico médio da porção $=15 \mathrm{Kcal}$ e tamanho médio $=60 \mathrm{~g}$ ), totalizando 570 gramas/dia o consumo mínimo de frutas, legumes e verduras. Essa recomendação supera em gramas o valor mínimo recomendado pela OMS (400 gramas/dia), valorizando a utilização dos alimentos regionais, os alimentos de estação e a variabilidade do consumo desses alimentos nas diferentes refeições e ao longo da semana. ${ }^{9}$

O WCRF e o AICR recomendam consumo mínimo de 400 gramas (5 porções de hortaliças sem amido e frutas/dia), ampliando essa medida para 600 gramas /dia para a prevenção de cânceres e outras doenças crônicas. ${ }^{6}$

Neste estudo verificou-se que $73,5 \%$ dos indivíduos consumiram abaixo de 400 gramas de frutas, verduras e legumes e 91,7\% abaixo de 600 gramas. Vale ressaltar que $20,4 \%$ dos indivíduos apresentaram consumo abaixo de $1,0 \%$ da energia da dieta e que $8,8 \%$ indivíduos não consumiram nenhuma Fr,V\&L. Os resultados encontrados são preocupantes, mas mostram-se 
positivamente diferenciados em relação aos dados encontrados em outros estudos, uma vez que o consumo médio em gramas ajustado por energia foi de $281,36 \mathrm{~g}$ por dia.

Bonard (2009) $)^{19}$, em estudo semelhante realizado no mesmo município com usuários de uma Unidade de Saúde da Família, verificou que 85,8\% da população ficou abaixo da recomendação da OMS e cujo consumo médio diário em gramas foi de 202,10 g por dia.

A análise realizada pela POF nos períodos de 1974 a 2003 mostra que a participação de frutas, legumes e verduras no valor energético total fornecido pela alimentação das famílias brasileiras era baixa, independente da faixa de renda, variando de 3\% a 4\% da energia total da alimentação, muito abaixo da recomendação da OMS. ${ }^{9}$

No presente estudo observou-se que o consumo de Fr,V\&L em porcentagem de energia médio foi igual a $8,72 \%$ de energia total da dieta (1529,55 Calorias), sendo superior ao consumo encontrado na POF - 1974 a 2003, assim como em outros estudos e aproximando-se da recomendação de $9 \%$.

Esse resultado contrasta com os encontrados por Levy-Costa et al $(2005)^{12}$, em estudo de base populacional realizado a partir de dados da POF 2002-2003, segundo o qual as frutas e hortaliças correspondiam a apenas 2,3\% das calorias totais da dieta, destacando ainda que a participação das Fr,V\&L na dieta aumentava de forma uniforme com o nível de rendimento familiar.

Contrasta também com os achados de Enes \& Silva (2007) ${ }^{32}$ em estudo sobre disponibilidade de energia e nutrientes presentes nos alimentos disponíveis nos domicílios entre as regiões Norte e Sul do Brasil. Esses autores analisaram a participação relativa dos macronutrientes no valor energético total e a contribuição dos diferentes grupos alimentares na energia disponível, segundo o rendimento mensal familiar. Verificaram que as famílias com maior renda (15 a 20 salários) apresentaram as maiores contribuições das frutas, 
verduras e legumes para o total de energia disponível nos domicílios, alcançando a recomendação da OMS, e que as famílias com baixa renda $(\leq 2$ salários) apresentaram consumo de frutas, verduras e legumes $50 \%$ menor que o recomendado, ou seja, em torno de $4,5 \%$.

De modo coerente com os dados da literatura, observou-se no presente trabalho que as mulheres apresentaram um maior consumo de frutas, verduras e legumes do que os homens, particularmente aquelas com sobrepeso e obesidade, e que houve aumento do consumo para aquelas pessoas com maior nível de escolaridade, enquanto indicador socioeconômico, como também para aquelas com excesso de peso corporal (sobrepeso). Também em conformidade com a literatura, constatou-se no grupo estudado que o consumo de $\mathrm{Fr}, \mathrm{V} \& \mathrm{~L}$ em porcentagem de energia, cresce com o aumento da idade.

Sichieri et al (2003) ${ }^{33}$ em estudo sobre fatores associados ao padrão de consumo alimentar da população brasileira urbana, observaram que a renda e escolaridade foram as variáveis que mais explicaram o consumo alimentar.

Nessa mesma direção, inquérito domiciliar sobre comportamentos de risco e morbidade referida de doenças e agravos não transmissíveis em 15 capitais brasileiras e no Distrito Federal, observou que o consumo de frutas, verduras e legumes foi mais freqüente entre as mulheres do que entre os homens e menor nos grupos mais jovens e entre as pessoas com menor nível de escolaridade. ${ }^{7}$

Figueiredo et al (2008) ${ }^{15}$ em estudo transversal, realizado na cidade de São Paulo, também observaram que as mulheres apresentaram maior freqüência de consumo de frutas, legumes e verduras do que os homens e a maior freqüência de consumo desses alimentos ocorreu entre aqueles que possuíam maior escolaridade e entre os indivíduos mais velhos em ambos os sexos. Ainda em outro estudo realizado no Brasil, Jaime \& Monteiro (2005) ${ }^{13}$, observaram que a freqüência do consumo de frutas e hortaliças tendia a ser maior entre as mulheres do que entre os homens, mas com consumo inadequado desses alimentos para ambos os sexos. O consumo de frutas e 
hortaliças era maior nas áreas urbanas do que em zonas rurais e tendia a aumentar com a idade, escolaridade e disponibilidade de bens domésticos.

Dados semelhantes também têm sido encontrados em pesquisas internacionais. Baker \& Wardle $(2003)^{34}$ em estudo realizado com adultos no Reino Unido observaram que o consumo de frutas e hortaliças era maior entre as mulheres do que entre os homens, e que ambos consumiam abaixo da recomendação de 5 porções por dia de frutas e vegetais, sendo 3,5 porções/dia para as mulheres e 2,5 porções/dia para os homens.

A condição socioeconômica, aqui indicada pela escolaridade, em parte concorda com a literatura ao apresentar uma relação direta de crescimento quanto maior a escolaridade maior o consumo de Fr,V\&L. No entanto, deve-se assinalar que, no grupo estudado, 68,51\% têm no máximo até 7 anos de escolaridade, dos quais perto de $50 \%$ têm até 4 anos.

Quando relacionamos o consumo de $\mathrm{Fr}, \mathrm{V} \& \mathrm{~L}$ às doenças diagnosticadas observamos que houve um maior consumo de $\mathrm{Fr}, \mathrm{V} \& \mathrm{~L}$, em gramas, ajustado e em porcentagem de energia, nos indivíduos com hipertensão, diabetes, DCV e hipotireoidismo. De modo inverso, nos indivíduos com diagnóstico de dislipidemia e intolerância à glicose, o consumo foi menor do que nos demais.

Essa tendência também foi verificada por Palma et al $(2009)^{35}$ em estudo sobre fatores associados ao consumo de frutas, verduras e legumes em NipoBrasileiros, avaliado pela análise de três inquéritos realizados por meio de recordatórios de 24 horas. Esses autores observaram tendência ao consumo adequado de Fr,V\&L entre indivíduos de maior idade, com menor freqüência de consumo de bebidas alcoólicas e maior adesão à prática de atividade física. Observaram também uma relação direta entre a elevação do consumo de Fr,V\&L e a frequência de morbidades como diabetes, hipertensão, dislipidemia e obesidade abdominal, tanto para o grupo dos indivíduos com um perfil de consumo adequado, como para aqueles com um perfil de consumo inadequado de frutas, verduras e legumes. Os indivíduos que relataram uma dieta habitual 
mais fracionada e com menor aporte de gorduras saturadas apresentaram maior chance de consumo de $400 \mathrm{~g} /$ dia de frutas, verduras e legumes.

Ao tomarmos para estudo a população adulta usuária de uma Unidade Básica de Saúde e que se encontra em seguimento, estamos considerando um conjunto de pessoas que necessariamente apresenta alguma condição de saúde específica que motiva a continuidade desse atendimento, ou seja, é portadora de uma condição crônica que está sendo abordada pela unidade de saúde. Com isso queremos assinalar que a população em estudo diferencia-se da população em geral tanto em seu particular perfil de saúde como também na exposição a diferentes modalidades de atendimento e abordagem nutricional presentes na unidade - desde as intervenções de sala de espera, os atendimentos nutricionais individuais e/ou em grupo, assim como a orientações dadas nos atendimentos médicos e de enfermagem.

Pode-se verificar que os indivíduos que participaram de atendimento nutricional individual apresentaram maior consumo de frutas, verduras e legumes, o que sugere uma resposta positiva a essa atividade. Assim como observamos um maior consumo entre os portadores de doenças crônicas mais conhecidas e com sintomatologia mais característica, como diabetes, DCV e hipotireoidismo, o mesmo não ocorrendo entre os portadores de alterações que isoladamente são assintomáticas, como a dislipidemia e a intolerância à glicose.

Deve-se considerar que aqueles que já se encontram em atendimento nutricional já se apresentam como indivíduos sensibilizados e mais propensos a melhorar sua alimentação, assim como aqueles que mesmo não estando em seguimento nutricional específico, reconhecem suas condições de saúde como merecedoras de um maior autocuidado por apresentarem múltiplas patologias.

O particular perfil da população estudada pode em parte explicar os valores de consumo de $\mathrm{Fr}, \mathrm{V} \& \mathrm{~L}$ em porcentagem média de energia da dieta fornecida igual a 8,72\%, próximo do recomendado e muito acima do encontrado em estudos de base populacional. Esse resultado, ainda que 
componha com uma média de ingestão diária em gramas distante do recomendado, aponta para uma maior disponibilidade desse grupo para aderir às orientações de uma dieta saudável.

Barreto \& Figueiredo $(2009)^{23}$ observaram em estudo sobre doença crônica, auto-avaliação e comportamento de risco, realizado em 27 capitais brasileiras em 2006, que os indivíduos com diagnóstico de doença crônica não transmissível referem mudanças no modo de vida, como menor consumo de sal e gordura e diminuição do tabagismo, relacionadas à presença dessa condição. Assinalam também que os portadores de doenças crônicas não transmissíveis freqüentam mais os serviços de saúde e recebem orientações para mudarem seus comportamentos com relação a dieta, tabagismo e outros comportamentos de risco.

Toral \& Slater $(2007)^{21}$ em estudo sobre comportamento alimentar, apontam como um dos determinantes para que os indivíduos levem em consideração os comportamentos relacionados à saúde é a percepção e a convicção do indivíduo de que a ação recomendada reduziria a ameaça à sua saúde. Em outras palavras, assinalam que reconhecer a necessidade de alteração dos hábitos alimentares é um requisito fundamental para iniciar uma mudança dietética.

A Unidade Básica de Saúde onde se desenvolveu o estudo parece ter um relativo sucesso em suas estratégias de intervenções nutricionais com vistas ao controle das DANT entre seus usuários, dado que adultos atendidos por este serviço apresentaram consumo de frutas, verduras e legumes superior ao de outros grupos e populações, e também pelo fato de indivíduos alvo de ações específicas de orientação alimentar terem apresentado consumo superior aos demais.

Como pudemos observar em grande parte dos trabalhados citados e conforme afirmam Jaime \& Monteiro (2005) ${ }^{13}$, a maioria dos estudos realizados no Brasil, são de base populacional ou baseados em inquéritos sobre orçamento familiar realizado pelo Instituto Brasileiro de Geografia e Estatística 
- IBGE, cujos dados revelam a disponibilidade média de alimentos no ambiente familiar e não o consumo individual. Além disso, pudemos observar na literatura consultada uma grande heterogeneidade de métodos utilizados para avaliação do consumo alimentar de Fr,V\&L: recordatórios alimentares de 24 horas (três dias), questionário de freqüência alimentar, questionário alimentar aplicado por telefone, entrevistas telefônicas, entre outros, assim como há diferenças na própria definição e categorização do consumo de Fr,V\&L.

Nesse sentido, o presente estudo se diferencia ao avaliar o consumo médio individual de $\mathrm{Fr}, \mathrm{V}, \& \mathrm{~L}$, em gramas e em porcentagem de energia total da dieta, utilizando como método o recordatório alimentar de 24h (um dia). Esse desenho traz limites, mas também vantagens aos seus resultados.

Ao focar sua análise em usuários de um único serviço, ganha em especificidade e conhecimento sobre esse particular grupo populacional e perde em capacidade de generalização de seus resultados, ainda que esses se mostrem coerentes com os encontrados em estudos de base populacional. Por outro lado, permite a identificação do consumo médio individual diferenciandose em relação aos estudos que se baseiam na disponibilidade de alimentos e/ou consumo familiar.

Deve-se destacar ainda que embora a aplicação de apenas um recordatório possa implicar em limites na acurácia da avaliação do consumo individual, há autores, como Pereira e Sichieri (2007) ${ }^{36}$, que acreditam que o consumo alimentar de um dia pode ser aceitável para a estimativa de médias de consumo total de energia, macronutrientes e micronutrientes de grupos populacionais específicos. A confirmação da validade desse método, preliminarmente apontada pela coerência de seus resultados com estudos realizados a partir de outras metodologias de aferição de consumo, pode ser de grande aplicabilidade nas práticas dos serviços por sua maior simplicidade e baixo custo. 
Em linhas gerais, os resultados sugerem que indivíduos com condições crônicas, em seguimento numa unidade de atenção primária à saúde, estão mais sensibilizados em cuidar da saúde e que, expostos a abordagens nutricionais, podem tornar-se mais suscetíveis a mudanças alimentares. Por outro lado, ampliar o alcance de ações entre os usuários da unidade estudada requer o desenvolvimento de abordagens de incentivo ao consumo de $\mathrm{Fr}, \mathrm{V}, \& \mathrm{~L}$ dirigidas a usuários mais jovens, do sexo masculino, com menor escolaridade e que não estejam em acompanhamento nutricional específico. 


\section{Canclusãa}

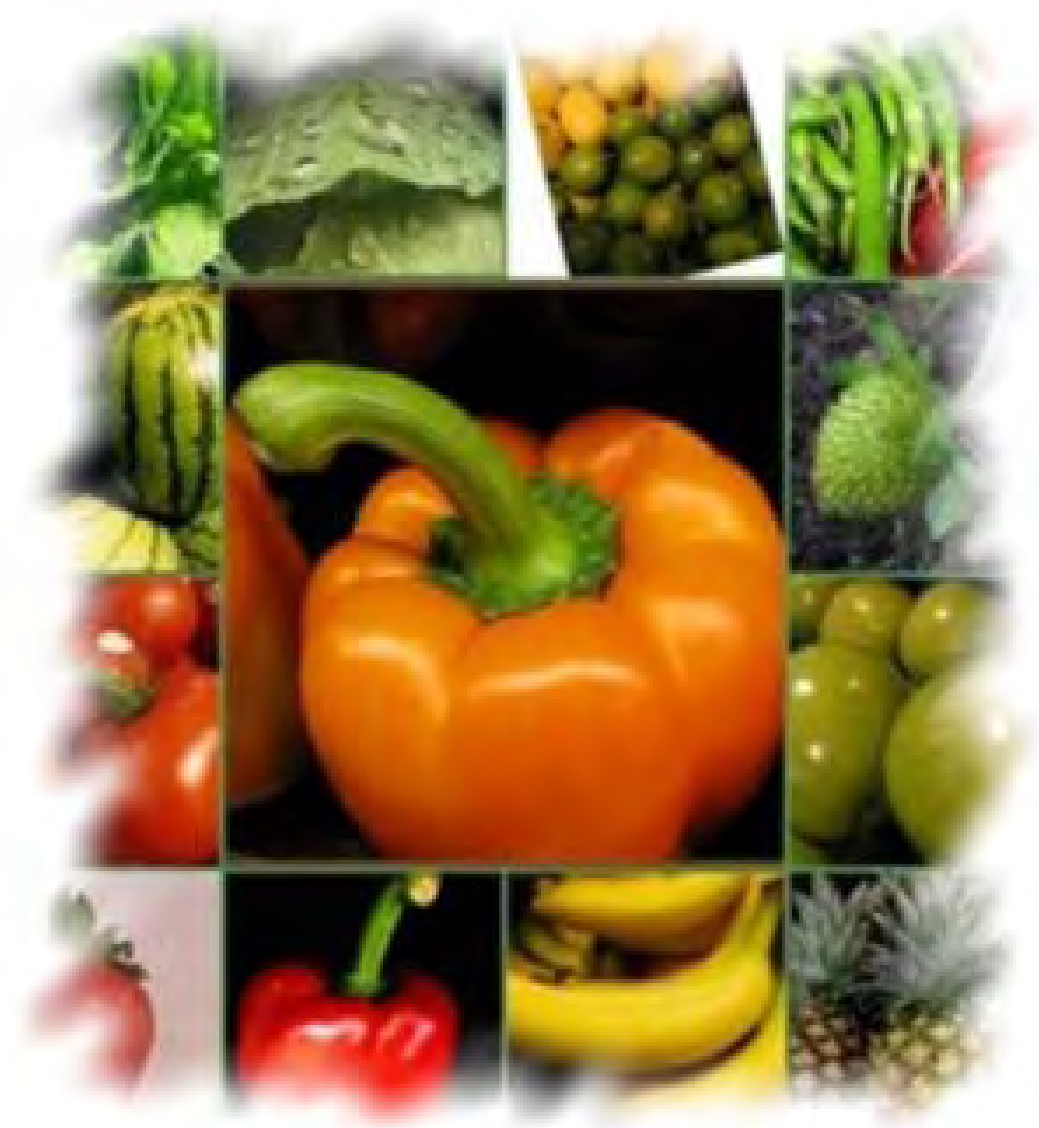


O conhecimento do consumo de frutas, verduras e legumes ( $F r, V \& L)$, bem como dos fatores associados a esse consumo, em uma população adulta assistida em serviço de atenção primária, é importante para orientar e avaliar estratégias e intervenções no âmbito da atenção básica. Toral \& Slater $(2007)^{21}$ mencionam que a ampliação do conhecimento sobre os inúmeros determinantes do comportamento alimentar é uma importante ferramenta para superar os desafios de transformar informações científicas de nutrição em mudanças reais das práticas alimentares.

Podemos destacar, em síntese, como resultados de maior relevância as seguintes questões:

1 - O consumo de Fr,V\&L na população usuária de serviço de atenção primária à saúde do interior do estado de São Paulo foi maior do que o reportado por estudos nacionais: o consumo médio, ajustado por energia, igual a 281,36 gramas $(D P=274,70)$ e porcentagem média de energia da dieta fornecida por este grupo alimentar igual a 8,72\%, valor próximo ao mínimo recomendado pela OMS (9\%). Entretanto 40,9 \% dos indivíduos alcançaram essa recomendação, destacando-se que 30,9\% dos indivíduos não consumiram nenhuma fruta, 38,1\% nenhuma verdura e 50,8\% nenhum legume, e ainda que cerca de $8,83 \%$ não consumiram nenhum alimento do grupo de Fr,V\&L. Estes resultados indicam que há necessidade de aperfeiçoar as ações visando incentivo ao consumo deste grupo alimentar no contexto local.

2 - Foram consumidos 49 itens do grupo alimentar de Fr,V\&L, sendo os doze mais consumidos: alface, laranja/mexerica, banana, tomate, mamão, cenoura, maçã, pepino, rúcula, limão, repolho e abobrinha, alimentos amplamente disponíveis e economicamente mais acessíveis no contexto local. Estes dados serão úteis para a construção de questionário de freqüência simplificado que permita avaliação rápida de indivíduos em maior risco de consumo insuficiente deste grupo alimentar. 
3 - Houve associação do consumo de Fr,V\&L (em porcentagem de energia) com sexo, sendo o consumo maior entre as mulheres; com estado nutricional, sendo o maior valor observado em indivíduos com sobrepeso; e com a participação em atendimento nutricional individual, na comparação com não participantes. Estudos futuros se fazem necessários para testar a efetividade de intervenções visando incentivar o consumo de Fr,V,\&L, particularmente nos seguimentos de mais baixo consumo: adultos mais jovens, homens, e nos menos escolarizados. Estudos qualitativos sobre os determinantes culturais e emocionais do consumo deste grupo alimentar também devem ser realizados.

Estes resultados justificam e recomendam a condução de estudo tipo ensaio randomizado, para confirmação dos efeitos positivos das ações envolvendo orientação nutricional. Outros estudos se fazem necessários, para avaliar o consumo de $\mathrm{Fr}, \mathrm{V}, \& \mathrm{~L}$ em crianças e jovens e testar intervenções dirigidas a estes grupos, visando a prevenção primária das DANT. Além disso, estudos com abordagens que permitam a análise dos fatores culturais e emocionais também são importantes para o delineamento de intervenções com maior potencial de efeito positivo. 


\section{Referencias}

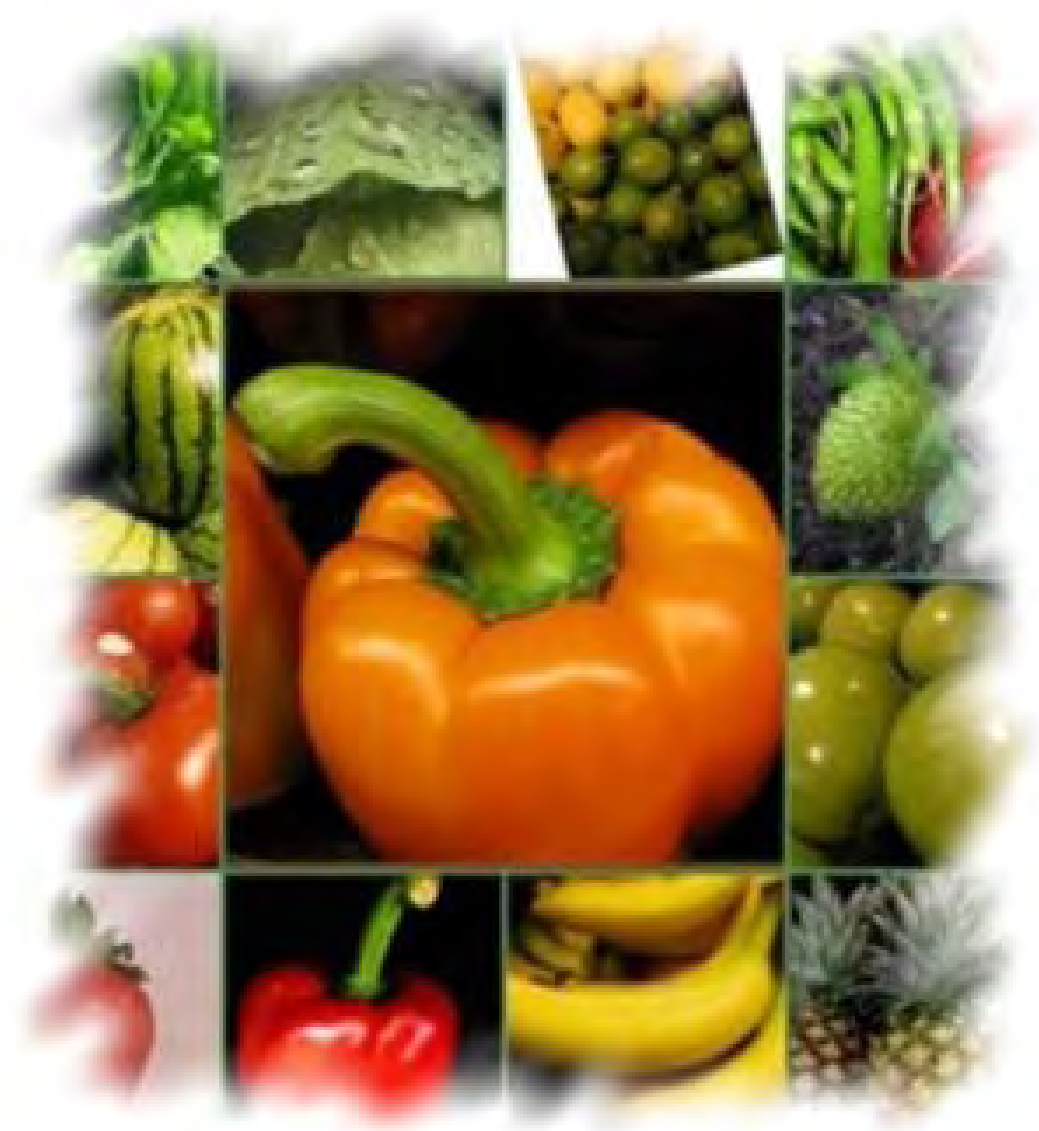


1. OPAS - Organização Pan-Americana da Saúde. Doenças crônicasdegenerativas e obesidade: Estratégia mundial sobre alimentação saudável, atividade física e saúde. Brasília: OPAS; 2003.

2. Brasil. Ministério da Saúde. Secretaria de Vigilância em Saúde. Secretaria de Gestão Estratégica e Participativa. Vigitel Brasil 2008: vigilância de fatores de risco e proteção para doenças crônicas por inquérito telefônico. Brasília: Ministério da Saúde; 2009.

3. Ministério da Saúde. Portaria n596, de 08 de abril de 2004. Análise da estratégia global para a alimentação saudável, atividade física e saúde. Brasília: Ministério da Saúde; 2004.

4. Ministério da Saúde. A iniciativa de incentivo ao consumo de frutas, legumes e verduras (F,L\&V) no Brasil: documento Base - 2005. Brasília: Ministério da Saúde; 2005.

5. Garófolo A, Avesani CM, Camargo KG, Barros ME, Silva SRJ, Taddei JAAC, et al. Dieta e câncer: um enfoque epidemiológico. Rev Nutr. 2004; 17:491-505.

6. World Cancer Research Fund. American Institute for Cancer Research [Internet]. Food, nutrition, physical activity, and prevention of cancer: a global perspective. Washington: IARC; 2007 [update 2009 oct 10]. Available from: http://www.dietandcancerreport.org/ .

7. Ministério da Saúde. Secretaria de Vigilância a Saúde. Secretaria de Atenção a Saúde. Instituto Nacional de Câncer. Inquérito domiciliar sobre comportamentos de risco e morbidade referida de agravos não transmissíveis. Rio de Janeiro: INCA; 2003. 
8. Ministério da Saúde. Secretaria de Atenção à Saúde. Instituto Nacional de Câncer. Coordenação de Prevenção e Vigilância. A situação do câncer no Brasil. Rio de Janeiro: INCA; 2006.

9. Ministério da Saúde. Secretaria de Atenção à Saúde. Departamento de Atenção Básica. Coordenação-Geral da Política de Alimentação e Nutrição. Diretrizes 3 Frutas, legumes e verduras. Brasília: Ministério da Saúde; 2006. p.51-58.

10. Campbell MK, Mc Lerran D, Turner G, Feng Z, Havas S, Sorensen G, et al. Mediation of adult fruit and vegetable consumption in the national 5 a Day for better health community studies. Ann Behav Med. 2008; 35:49-60.

11. www.5aodia.com.br [Internet]. Promoção do consumo de frutas, legumes e verduras: o programa "5 ao dia". [acesso 16 outubro 2009]. Disponível em: http://www.5aodia.com.br/upload/cartilha1.pdf

12. Levy-Costa RB, Sichieri R, Pontes NS, Monteiro CA. Disponibilidade domicilar de alimentos no Brasil: distribuição e evolução (1974-2003). Rev Saúde Pública. 2005;39:530-40.

13. Jaime PC, Monteiro CA. Fruit and vegetable intake by Brazilian adults, 2003. Cad Saúde Pública. 2005;21:19-24.

14. Moura EC, Neto OLM, Malta DC, Moura L, Silva NN, Bernal R, et al. Vigilância de fatores de risco para doenças crônicas por inquérito telefônico nas capitais dos 26 estados brasileiros e no Distrito Federal (2006). Rev Bras Epidemiol. 2008;11 supl 1:20-37.

15. Figueiredo ICR, Jaime PC, Monteiro CA. Fatores associados ao consumo de frutas, legumes e verduras em adultos da cidade de São Paulo. Rev Saúde Pública. 2008;42:777-85. 
16. Jorge MIE, Martins IS, Araújo EAC. Diferenciais socioeconômicos e comportamentais no consumo de hortaliças e frutas em mulheres residentes em município da região metropolitana de São Paulo. Rev Nutr. 2008; 21:695-703.

17. Fisbeg RM, Slater B, Barros RR, Lima FD, Cesar CLG, Carandina L, et al . Índice de Qualidade da Dieta: avaliação da adaptação e aplicabilidade. Rev Nutr. 2004; 17:301-8.

18. Carvalhaes MABL, Moura EC, Monteiro CA. Prevalência de fatores de risco para doenças crônicas: inquérito populacional mediante entrevistas telefônicas em Botucatu, São Paulo, 2004. Rev Bras Epidemiol. 2008; 11:14-23.

19. Bonard IS. Determinantes da qualidade alimentar de adultos e idosos atendidos em uma Unidade de Saúde da Família (Rubião Junior, Botucatu, SP) [dissertação]. Botucatu: Faculdade de Medicina, Universidade Estadual Paulista; 2009.

20. Cyrino AP, Schraiber LB. O projeto centro de saúde escola em ação e os impasses do cotidiano. In: Cyrino AP, Magaldi C. Saúde e comunidade: 30 anos de experiência de extensão universitária em Saúde Coletiva. Botucatu: Cultura Acadêmica; 2002.

21. Toral N, Slater B. Abordagem do modelo transteórico no comportamento alimentar. Ciênc Saúde Coletiva. 2007; 12:1641-50.

22. Rossi A, Moreira EA, Rauen MS. Determinantes do comportamento alimentar: uma revisão com enfoque na família. Rev Nutr. 2008; 21:739-48.

23. Barreto SM, Figueiredo RC. Doença crônica, auto-avaliação de saúde e comportamento de risco: diferença de gênero. Rev Saúde Pública. 2009; 43:38-47. 
24. Nielsen SJ, Adair L. An alternative to dietary data exclusions. J Am Diet Assoc. 2007; 107:792-9.

25. Fagundes AA, Barros DC, Duar HA, Sardinha LMV, Pereira MM, Leão MM. Vigilância alimentar e nutricional - SISVAN: orientações básicas para coleta, processamento, análise de dados e informação em serviços de saúde. Brasília: Ministério da Saúde; 2004.

26. Fisberg RM, Marchioni DML, Colucci ACA. Avaliação do consumo alimentar e da ingestão de nutrientes na prática clínica. Arq Bras Endocrinol Metab. 2009; 53:617-24.

27. Philippi ST. Tabela de composição de alimentos: suporte para decisão nutricional. 2ªed. São Paulo: Coronário; 2002.

28. Pinheiro ABV, Lacerda EMA, Benzecry EH, Gomes MCS, Costa VM. Tabela para avaliação de consumo alimentar em medidas caseiras. $4^{\mathrm{a}} \mathrm{ed}$. São Paulo: Atheneu; 2002.

29. Núcleo de Estudos e Pesquisas em Alimentação - NEPA. Tabela brasileira de composição de alimentos/ NEPA -UNICAMP. Versão II. $2^{\mathrm{a} e d .}$ Campinas: NEPA-UNICAMP; 2006.

30. Jaime PC, Latorre MRDO, Fornés NS, Zerbini CAF. Estudo comparativo entre dois métodos de ajuste energético do consumo de nutrientes. Nutrire: rev Soc Bras Aliment Nutr. 2003; 26:11-8.

31. Viebig RF, Valero MP. Desenvolvimento de um questionário de freqüência alimentar para o estudo de dieta e doenças não transmissíveis. Rev Saúde Pública. 2004; 38:581-4. 
32. Enes CC, Silva MV. Disponibilidade de energia e nutrientes nos domicílios: o contraste entre as regiões Norte e Sul do Brasil. Ciênc Saúde Coletiva. 2009; 14:1267-6.

33. Sichieri R, Castro JFG, Moura AS. Fatores associados ao padrão de consume alimentar da população brasileira urbana. Cad Saúde Pública. 2003; 19:47-53.

34. Baker $\mathrm{AH}$, Wardle J. Sex differences in fruit and vegetable intake in older adults. Appetite. 2003;40:269-75.

35. Palma RFM, Barbieri P, Damião R, Polleto J, Chaim R, Gimeno SG, et al. Fatores associados ao consumo de frutas, verduras e legumes em NipoBrasileiros. Rev Bras Epidemiol. 2009; 12:436-45.

36. Kac G, Sichieri R, Gigante DP, organizadores. Epidemiologia nutricional. Rio de Janeiro: Fiocruz; 2007. 


\section{Anexas}

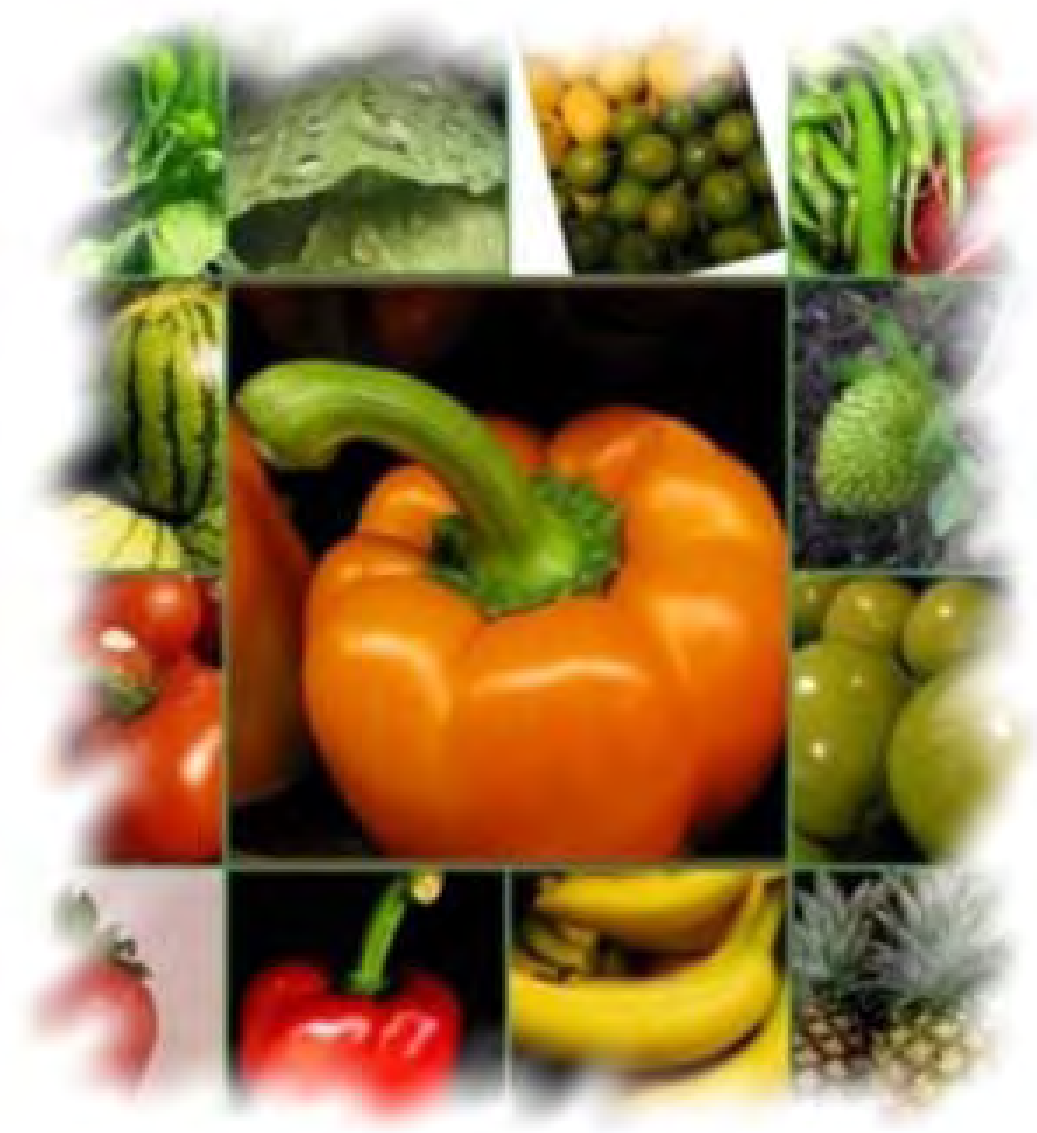


Anexo 1 - Recordatório Alimentar de 24 horas.

DN: $\quad$ I

Nome:

No matrícula

DATA: $\quad$ I $/ 07$

O(A) Senhor(a) considera sua alimentação: （ ) saudável （）normal （） não saudável Utiliza: ( ) mascavo ( ) refinado ( ) cristal ( ) adoçante ( ) mel ( ) outros Que tipo de gordura utiliza: ( ) soja ( ) azeite ( ) banha ( ) manteiga ( ) outros Quantas latas de óleo/mês utiliza __ und.(s) alimentam__ no pessoas ( ) não informado $O$ alimento da sua casa tem aparência: ( ) oleosa ( ) normal ( ) seca

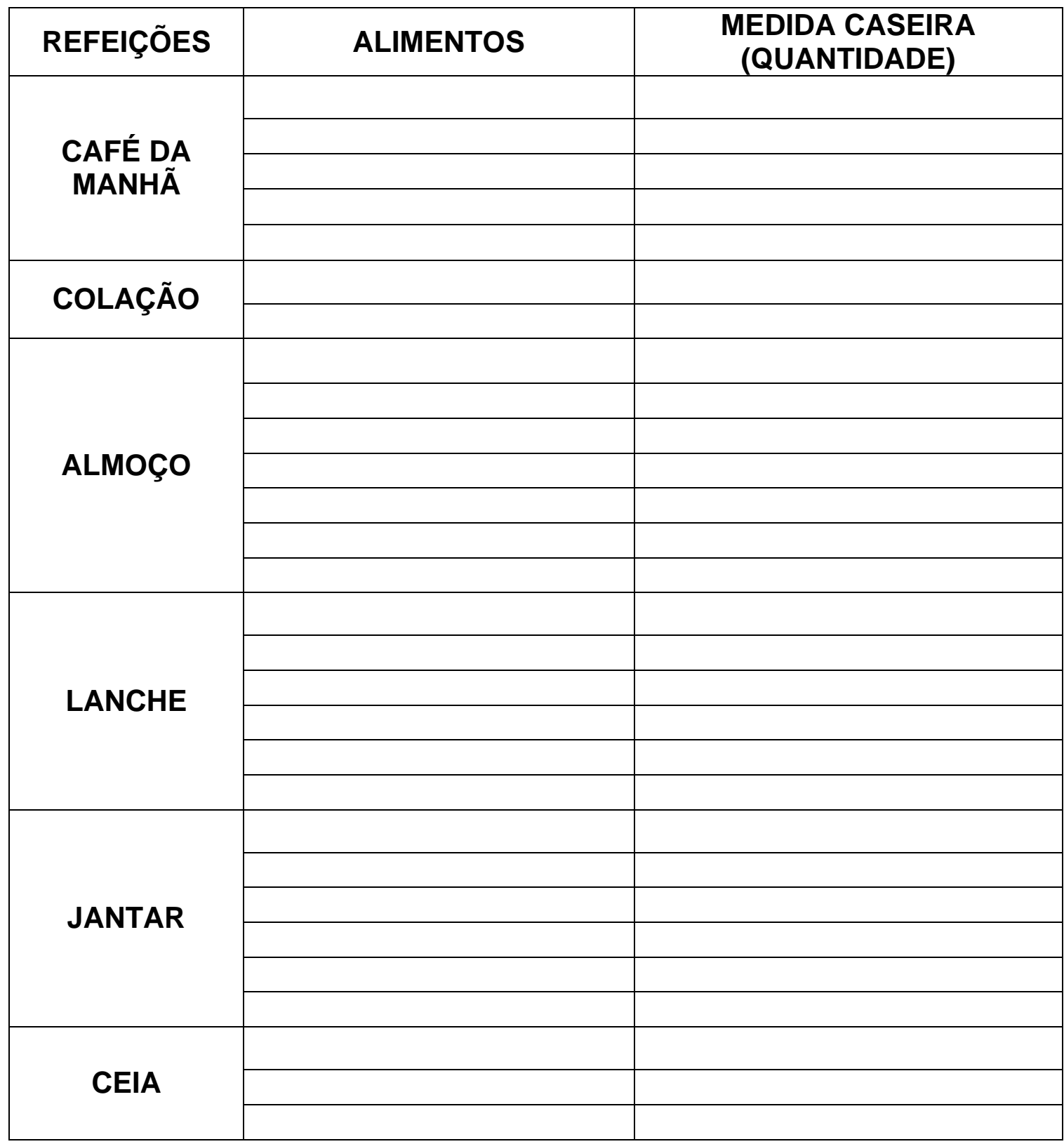




\section{Anexo 2 - Formulário.}

\section{Nome:}

No matrícula:

Data R24h:

Data :

Telefone:

1. Data Nascimento: Dia/ mês/ ano

Idade: anos

$$
\begin{aligned}
& \text { 2.Sexo: 1( )F 2( )M } \\
& \text { 3.Escolaridade: } \\
& 0-3 \text { anos ( ) } \\
& 4-7 \text { anos ( ) } \\
& 8-11 \text { anos ( ) } \\
& \geq 12 \text { anos ( ) }
\end{aligned}
$$

\section{Características Nutricionais:}

Peso(Kg): $\quad$ Altura $(\mathrm{cm}):$ $\operatorname{IMC}\left(\mathrm{Kg} / \mathrm{m}^{2}\right)$ :

\section{Características de Saúde:}

Morbidades pessoais diagnosticadas:

DM 1( ) HA 2( ) DCV 3( ) Dislipidemia 4( ) intolerância a glicose 5( ) Hipotireoidismo 6( ) outros $7($ )

\section{Uso do Servico:}

Atendimento Nutricional individual - 1( ) sim 0 ( ) não

Atividade Educativa em grupo - $\quad 1$ ( ) sim 0 ( ) não

- Indicadores socioeconômico e sócio-demográficos • Características Nutricionais, de Saúde e Uso do serviço 
Anexo 3 - Parecer comitê de ética.

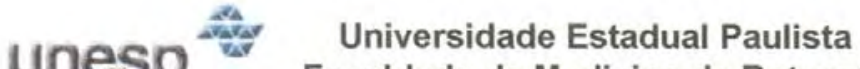 Faculdade de Medicina de Botucatu}

Distrito Rubião Junior, $s / n^{\circ}$ - Botucatu - S.P.

CEP: $18.618-970$

Fone/Fax: $(0 x \times 14) 3811-6143$

e-mail secretaria: capellup@fmb.unesp.br

Registrado no Ministério da Saúde em 30 de

abril de 1997

Botucatu, 05 de março de 2.007

OF. 21/2007-CEP

Ihustrissima Senhora

Prof". Dr ${ }^{a}$.Elen Rose L. Castanheira

Departamento de Saúde Pública

Faculdade de Medicina de Botucatu

Prezada Dr ${ }^{a}$ Elen,

De ordem da Senhora Coordenadora deste CEP, informo que o Projeto de Pesquisa "Caracterização e avaliação do consumo alimentar de frutas, verduras e legumes em adultos na atenção primária", a ser conduzido por Estela Maria Barin, orientada por Vossa Senhoria e Co-orientada pela Prof ${ }^{a} \mathrm{Dr}^{a}$ Maria Antonieta de Barros Leite Carvalhães, recebeu do relator parecer favorável, aprovado em reunião de 05/03/2007.

Situação do Projeto: APROVADO.

OBS: Ao final da execução deste projeto, deverá ser apresentado ao CEP "Relatório Final de Atividades".

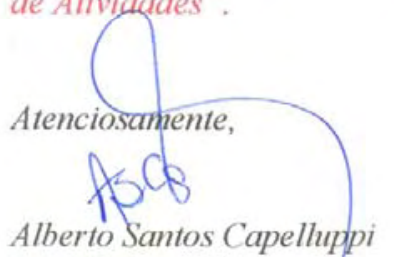

Secretário do CEP. 
Anexo 4 - Termo de consentimento livre e esclarecido.

\section{TERMO DE CONSENTIMENTO LIVRE E ESCLARECIDO (TERMINOLOGIA OBRIGATÓRIO EM ATENDIMENTO A RESOLUÇÃO 196/96 -CNS-MS)}

\section{"Caracterização e avaliação do consumo alimentar de frutas, verduras e legumes em adultos na atenção primária."}

A intenção desta pesquisa é caracterizar e avaliar o consumo alimentar de frutas, verduras e legumes ( $F r, V \& L)$ em uma população adulta atendida no Centro de Saúde Escola F.M.B. e identificar fatores associados ao consumo desses alimentos.

Para a realização dessa pesquisa, faremos algumas perguntas relacionadas aos hábitos alimentares, à freqüência do consumo de $\mathrm{Fr}, \mathrm{V} \& \mathrm{~L}$ e sobre condições e hábitos de vida como profissão, ocupação, idade, composição da família, doenças, atividade física, entre outras.

A pesquisa não apresentará risco, desconforto e inconveniências para nenhum indivíduo, já que constará de apenas perguntas com respostas rápidas e objetivas. Os dados coletados serão confidenciais, e, na publicação da pesquisa, as suas informações aparecerão na forma de números, porcentagens, sem identificação. Em nenhuma circunstância aparecerá seu nome e endereço.

A sua participação nesta pesquisa estará contribuindo o planejamento de atividades educativas dirigidas a estimular o consumo destes alimentos entre a clientela de serviços de saúde.

Você receberá uma cópia deste termo de consentimento para a sua informação e arquivo. Qualquer dúvida, questão, esclarecimento ou reclamação sobre os aspectos éticos desta pesquisa, favor entrar em contato com a pesquisadora responsável pelo telefone: (14) 9775-1613 ou pelo e-mail:estelabarim@terra.com.br, ou com a orientadora responsável pelo telefone: (14) 9798-4834 ou pelo e-mail: elen@fmb.unesp.br.

Desde já, agradecemos a sua participação.

Eu, abaixo descrito e assinado, declaro que fui esclarecido(a) sobre a pesquisa "Caracterização e avaliação do consumo alimentar de frutas, verduras e legumes em adultos na atenção primária" e concordo em participar da mesma, respondendo as perguntas que forem formuladas.

Nome:

Endereço:

Bairro: Cidade: Estado:

Matrícula:

Data:

1

Botucatu - S.P.

Assinatura:

Paciente

Pesquisadora:

Nutricionista Estela Maria Barim

Rua Prudente de Morais, 455, Centro - Botucatu-SP

Tel:(14) 3882-0356 - Cel:(14) 9775-1613

e-mail:estelabarim@terra.com.br

\section{Pesquisadora}

Orientadora:

Prof $^{a}$ Dr $^{a}$ Elen Rose Lodeiro Castanheira

Rua Octacílio Nogueira, 469 - Botucatu-SP

Tel:(14) 3813-2554 - Cel:(14) 9798-4834

e-mail:elen@fmb.unesp.br 